\title{
Characterization of the microbiome of the invasive Asian toad in Madagascar across the expansion range and comparison with a native co-occurring species
}

\author{
Bárbara Santos ${ }^{\text {Corresp., } 1}$, Molly Bletz ${ }^{2}$, Joana Sabino-Pinto ${ }^{3}$, Walter Cocca ${ }^{1}$, Jean Francois solofoniaina fidy ${ }^{4}$, Karen \\ LM Freeman $^{4}$, Sven Kuenzel ${ }^{5}$, Serge Ndriantsoa ${ }^{6}$, Jean Noel ${ }^{4}$, Tsanta Rakotonanahary ${ }^{6}$, Miguel Vences ${ }^{3}$, \\ Angelica Crottini ${ }^{1}$ \\ ${ }^{1}$ Cibio, Research Centre in Biodiversity, Genetics and Evolution, InBio, Universidade do Porto, Campus Agrário de Vairão, Rua Padre Armando Quintas, 7 , \\ 4485-661 Vairão, Portugal., Porto, Portugal \\ 2 Department of Biology, University of Massachussetts Boston, Boston, MA, USA, Boston, USA \\ 3 Zoological Institute, Braunschweig University of Technology, Mendelssohnstr. 4, 38106 Braunschweig, Germany, Braunschweig, Germany \\ 4 Madagascar Fauna and Flora Group, BP 442, 501 Toamasina, Madagascar, Toamasina, Madagascar \\ 5 Max Planck Institute for Evolutionary Biology, August-Thienemann-Str. 2, 24306 Plön, Germany, Plön, Germany \\ 6 Amphibian Survival Alliance c/o Durrell Wildlife Conservation Trust, Madagascar Programme, Lot II Y 49 J 12 Ampasanimalo, BP 8511 101 Antananarivo, \\ Madagascar, Antananarivo, Madagascar \\ Corresponding Author: Bárbara Santos \\ Email address: barbarasantosbio@gmail.com
}

Biological invasions are on the rise, each invader carrying a plethora of associated microbes. These microbes play important, yet poorly understood, ecological roles that can include assisting the hosts in colonization and adaptation processes or as possible pathogens. Understanding how these communities differ in an invasion scenario may help to understand the host's resilience and adaptability. The Asian common toad, Duttaphrynus melanostictus is an invasive amphibian, which has recently established in Madagascar and is expected to pose numerous threats to the native ecosystems. We characterized the skin and gut bacterial communities of $D$. melanostictus in Toamasina (Eastern Madagascar), and compared them to those of a co-occurring native frog species, Ptychadena mascareniensis, at three sites where the toad arrived in different years. Microbial composition did not vary among sites, showing that $D$. melanostictus keeps a stable community across its expansion but significant differences were observed between these two amphibians. Moreover, $D$. melanostictus had richer and more diverse communities and also harboured a high percentage of total unique taxa (skin: $80 \%$; gut: $52 \%)$. These differences may reflect the combination of multiple host-associated factors including microhabitat selection, skin features and dietary preferences. 


\section{Characterization of the microbiome of the invasive Asian toad in Madagascar} 2 across the expansion range and comparison with a native co-occurring species

3 Bárbara Santos $^{1 *}$, Molly C. Bletz ${ }^{2}$, Joana Sabino-Pinto ${ }^{3}$, Walter Cocca ${ }^{1}$, Jean François Solofo Niaina Fidy ${ }^{4}$, Karen

4 LM Freeman ${ }^{4}$, Sven Kuenzel ${ }^{5}$, Serge Ndriantsoa ${ }^{6}$, Jean Noël ${ }^{4}$, Tsanta Rakotonanahary ${ }^{6}$, Miguel Vences ${ }^{3}$, Angelica

5 Crottini $^{1}$

$6{ }^{1}$ Cibio, Research Centre in Biodiversity, Genetics and Evolution, InBio, Universidade do Porto, Campus Agrário de

7 Vairão, Rua Padre Armando Quintas, 7, 4485-661 Vairão, Portugal.

82 Department of Biology, University of Massachussetts Boston, Boston, MA, USA

$9{ }^{3}$ Zoological Institute, Braunschweig University of Technology, Mendelssohnstr. 4, 38106 Braunschweig, Germany

$10 \quad{ }^{4}$ Madagascar Fauna and Flora Group, BP 442, 501 Toamasina, Madagascar

$11{ }^{5}$ Max Planck Institute for Evolutionary Biology, August-Thienemann-Str. 2, 24306 Plön, Germany

$12{ }^{6}$ Amphibian Survival Alliance c/o Durrell Wildlife Conservation Trust, Madagascar Programme, Lot II Y $49 \mathrm{~J}$

13 Ampasanimalo, BP 8511101 Antananarivo, Madagascar

*Corresponding author:

Bárbara Santos $^{1}$

Email address: barbarasantosbio@gmail.com

\section{Abstract}

Biological invasions are on the rise, each invader carrying a plethora of associated microbes. the hosts in colonization and adaptation processes or as possible pathogens. Understanding how these communities differ in an invasion scenario may help to understand the host's resilience and adaptability. The Asian common toad, Duttaphrynus melanostictus is an invasive amphibian, which has recently established in Madagascar and is expected to pose numerous threats to the native ecosystems. We characterized the skin and gut bacterial communities of D. melanostictus in Toamasina (Eastern Madagascar), and compared them to those of a co-occurring native frog species, Ptychadena mascareniensis, at three sites where the toad arrived in different years. Microbial composition did not vary among sites, showing that D. melanostictus keeps a stable community across its expansion but significant differences were observed between these two amphibians. Moreover, D. melanostictus had richer and more diverse communities and also 
harboured a high percentage of total unique taxa (skin: $80 \%$; gut: $52 \%$ ). These differences may reflect the combination of multiple host-associated factors including microhabitat selection, skin features and dietary preferences.

\section{Acknowledgments}

We are grateful to Meike Kondermann for helping with the laboratory work and to all the people who helped us in the field. We thank Javier Lóbon-Rovira for providing the photo of Ptychadena mascareniensis.

\section{Introduction}

Biological invasions can cause dramatic biodiversity loss (Enserink, 1999; Chornesky \& Randall, 2003; Penk et al., 2016), with climate change, habitat alterations and direct anthropogenic translocation being the main factors facilitating the worldwide spread of alien, invasive species (Alpert, Bone, \& Holzapfel, 2000; Stachowicz et al., 2002; Walther et al., 2009; Crooks, Chang \& Ruiz, 2011). Although alien invasive species do not always have detrimental effects (Schlaepfer, Sax, \& Olden, 2011), their potential devastating effects can be stronger in fragile island ecosystems. Here, they often out-compete or predate on local species, interfering with trophic networks and ultimately altering natural ecosystem function and balance (Lowe et al., 2000; Pitt, Vice, \& Pitzler, 2005). Among amphibians, notable invasive species include the Cane toad, Rhinella marina, the Puerto Rican Coquí, Eleutherodactylus coqui and the American bullfrog, Lithobates catesbeianus (Beard \& Pitt, 2005; Shine, 2010; Snow \& Witmer, 2010) of which the former is especially notorious for its negative effects in its invasive range in Australia. Among the many impacts that invasive species can have on native ecosystems, the introduction and spread of pathogenic fungi and viruses is also emerging as an important factor that may contribute to the global amphibian population decline (Miaud et al., 2016).

Microbiome research with high-throughput DNA sequencing techniques has enabled a better understanding of how host-associated microbiomes vary across host species, age, sex and habitats, and how their composition and diversity is influenced by host related and habitatdependent factors (McKenzie et al., 2012; Bletz, Perl, \& Vences, 2017; Tiede et al., 2017). 
62 Symbiotic microbial communities likely inhabit all multicellular organisms and play an 63 important role in the ecology, physiology, behaviour and health of their hosts (Dethlefsen, Mcfall-Ngai, \& Relman, 2007; Grice \& Segre, 2012; Abdallah, Mijouin \& Pichon, 2017; Lester et al., 2017). The skin microbiome can influence host's ability to cope with environmental and habitat conditions and mediate immune responses (Sandord \& Gallo, 2013; Grice, 2014; Jani \& Briggs, 2018; Rebollar et al., 2016; Xavier et al., 2019), while gut-associated microbes can aid in food digestion, energy harvesting, development or immunity (Turnbaugh et al., 2006; Heijitx et al., 2011; Tuddenham \& Sears, 2015). Microbiomes have been proposed to affect the host's capacity for colonization, adaptation, and boosting the immune system (Rout et al., 2013 Gribben et al., 2017; Cheng et al., 2018). For example, interactions between invasive plants and associated microbes were found to suppress the rhizosphere microbes and other beneficial symbionts in native plants (Coats \& Rumpho, 2014); on the contrary, some fungal symbionts were found to increase survival of their insect host, an invasive ant species, when these were exposed to pathogens (Konrad et al., 2014). In amphibians, only a few recent studies have evaluated the microbial communities in invasive species (e.g., Abarca et al., 2018; Christian et al., 2018; Kueneman et al., 2019).

Madagascar is one of the most celebrated biodiversity hotspots (Ganzhorn et al., 2001), known not only for the high degree of endemism but also for the ongoing loss of its original primary vegetation. Amphibian diversity in Madagascar is exceptionally high (Vieites et al., 2009; Perl et al., 2014; Brown et al., 2016) and severely threatened by habitat loss and human exploitation (Harper et al., 2007). Invasive species and pathogens in Madagascar are emerging as a new conservation concern since they may push native species further towards extinction (Bletz et al., 2015; Kull, Tassin \& Carriere, 2015; Goodman et al., 2017). A naturalized population of the Asian common toad, Duttaphrynus melanostictus, was reported in Madagascar in 2014, and has since become a major conservation concern (Andreone et al., 2014; Crottini et al., 2014; Kolby, 2014). Originally from Asia, it is estimated to have been present in Madagascar since 2010, being first reported near the seaport city of Toamasina, on Madagascar's eastern coast in 2014 (Fig 1; Kolby 2014). Duttaphrynus melanostictus is believed to have arrived from Cambodia or Vietnam (Vences et al., 2017), possibly in shipping containers. At present, it occurs mainly in urban and rural lands with mixed Eucalyptus spp. forests, where native amphibian communities are highly impoverished. However, it is rapidly expanding (Licata et al., 2019; 
93 Licata et al., 2020) and it is feared that it may soon reach areas known to host richer amphibian

94 communities such as Betampona Strict Nature Reserve and Parc Ivoloina (Rosa et al., 2012;

95 Crottini et al., 2014).

Although with low incidence, predation of smaller herpetofauna has been observed in other invasive populations of this toad (Döring et al., 2017), but the major concern of this invasion is associated with toad toxicity and the devastating effects that this species might have on its predators. In fact, D. melanostictus is known to produce highly poisonous skin toxins that are likely to negatively affect the vast majority of potential native predators (Marshall et al., 2018). Skin secretions isolated from $D$. melanostictus individuals collected in its native range seem to contain potent antimicrobial agents and important pharmacological compounds (Garg et al., 2007) that may increase disease resistance, making this invasive amphibian species a particularly interesting candidate for microbiome studies in invasive scenarios. Due to its life history traits that promote the capacity to reach high abundances and high dispersal rate, $D$. melanostictus is considered to have high invasive potential (Reilly et al., 2017; Licata et al., 2019; Licata et al., 2020). High invasive potential has been observed in other toad species such as $R$. marina, where this capacity has been linked to reduced ecological pressures in invaded areas and a rapid physiological adaptation to new environments (Phillips et al., 2006).

Here, we provide the first assessment of skin and gut bacterial communities of the its microbiome with that of a co-occurring native frog species, the Mascarene ridged frog (Ptychadena mascareniensis), across its expansion range. We hypothesized that the invasive species will present richer and more diverse bacterial assemblages due to intrinsic physiological and ecological characteristics, but also due to the recent introduction to a new environment (the invaded area). We also expect that across sites the toad may have different bacterial assemblages, due to the different arrival time in the new environment, while the native species, due to the limited geographic scale and similar habitat type, may exhibit similar bacterial assemblages. We explore the correlation between the toad's microbial diversity and its high colonization and adaptation capacity, using as proxy measures of bacterial species richness, diversity and functional inference that may confer disease resistance or enhance wider diet range

122 in different habitats. 
124 Methods

125 Sampling

126 The study species collected were the invasive Asian toad (Duttaphrynus melanostictus) and the

127 native and co-occurring species Mascarene ridged frog (Ptychadena mascareniensis). Sampling

128 was performed in the invaded area around Toamasina (eastern Madagascar) (Fig. 1) between

129 September $20^{\text {th }}$ and $24^{\text {th }}, 2016$. All sampling sites are highly anthropogenically transformed areas

130 and the selection of sampling sites was based on the known distribution of $D$. melanostictus at

131 the time (retrieved from Moore et al. (2015) and based on field observations carried out by the

132 staff of Madagascar Fauna and Flora Group). We aimed to analyse sites where the toad

133 established in different years (Fig. 1): Site 1 (green, S1), point where the toad was likely

134 introduced around 2010; Site 2 (orange, S2), site where the toad was not found in early 2014 and

135 detected only in late 2014; Site 3 (blue, S3), site that was recently colonized at the time of

136 sampling (September 2016). In each site we collected 16 individuals (8 males and 8 females) of

137 D. melanostictus and 4 individuals of the P. mascareniensis. Each specimen was collected with

138 new nitrile gloves, measured (snout-vent length and weight), and kept in individual sterile plastic

139 bags until sampling. Each specimen was rinsed with sterile water to remove debris and transient

140 microbes, and swabbed 10 times on the ventral side and five times on each thigh and foot using

141 one sterile swab (MW113, Medical Wire Equipment \& Co. Ltd., Corsham, United Kingdom).

142 Swabs were air dried, placed in their individual tube and kept at ca. $4^{\circ} \mathrm{C}$ during the expedition

143 and during the export from Madagascar, and transferred to $-20^{\circ} \mathrm{C}$ upon their arrival in Europe.

144 To characterize the gut bacterial communities for both species, at each site we used a solution of

145 Tricaine Methanesulfonate (MS-222, Sigma-Aldrich) to euthanize 4 individuals of $P$.

146 mascareniensis individuals and 4 (2 males and 2 females) of the 16 individuals of $D$.

147 melanostictus. After euthanasia the specimens were dissected and the gut (the entire intestine

148 portion including gut contents) was removed and stored in RNA later. For each site, we pooled

149 the dissected guts of the 4 D. melanostictus into one tube and the dissected guts of $P$.

150 mascareniensis into another tube. The 6 tubes with the pooled gut samples per site and per

151 species were kept in liquid nitrogen during fieldwork, transferred to cool conditions (ca. $4^{\circ} \mathrm{C}$ )

152 during the export from Madagascar, and stored at $-80^{\circ} \mathrm{C}$ upon their arrival to Europe.

DNA extraction, amplification and sequencing 
154 Gut tissue samples of each tube were homogenized. DNA from swabs and gut tissue was

155 extracted following a modified Qiagen DNeasy Blood \& Tissue Kit protocol (Hilden, Germany)

156 with an initial lysozyme incubation step at $37^{\circ} \mathrm{C}$ to break up cell walls of Gram-positive bacteria.

157 To enable comparison of our data with previously published studies on the microbiome of

158 Malagasy amphibians we amplified the V4 region of the bacterial 16S rRNA gene using the

159 following primer set: 515F (5'-GTGCCAGCMGCCGCGGTAA-3') and 806R (5'-

160 GGACTACHVGGGTWTCTAAT-3') (Caporaso et al., 2011). Amplification of each sample was

161 performed in duplicate in a volume of $12.5 \mu 1$ including $0.2 \mu 1$ of Phusion Hot Start II DNA

162 Polymerase (Thermo Fisher Scientific, Waltham, Ma, USA), $0.25 \mu 1$ of each primer $(10 \mu \mathrm{M})$,

$1630.25 \mu 1$ of dNTPs, $2.5 \mu 1$ of buffer, $8.1 \mu 1$ of $\mathrm{H}_{2} \mathrm{O}$ and $1 \mu 1$ of template DNA. The amplification

164 protocol consisted of an initial denaturation step at $98^{\circ} \mathrm{C}$ for $1 \mathrm{~min}$, followed by 30 cycles of

165 denaturation at $98^{\circ} \mathrm{C}$ for $10 \mathrm{~s}$, annealing at $55^{\circ} \mathrm{C}$ for $30 \mathrm{~s}$ and elongation at $72^{\circ} \mathrm{C}$ for $30 \mathrm{~s}$, with a

166 final extension at $72^{\circ} \mathrm{C}$ for $5 \mathrm{~min}$. The two PCR products of each sample were pooled together in

167 a total volume of $25 \mu 1$ and visualized on $1 \%$ agarose gel. All samples were pooled together

168 according to band brightness and the final pooled sample was run in a $1 \%$ agarose gel and

169 purified with QIAQuick Gel Extraction Kit (Qiagen, Hilden, Germany). Samples were

170 sequenced using paired-end 2 x 250 v2 chemistry on an Illumina MiSeq sequencing platform

171 using a dual-index approach (Kozich et al., 2013). Raw sequences were deposited in NCBI under

172 the following bioproject number D PRJNA667830.

\section{Sequence processing}

174 Sequences were processed in Quantitative Insights into Microbial Ecology (QIIME v1.9.1)

175 (Caporaso et al., 2010). Due to the typical lower quality of reverse reads (Kwon et al., 2013),

176 only the forward reads were filtered under the following criteria: absence of Ns within the

177 sequence, absence of barcode errors, and exclusion of reads containing at least three consecutive

178 low-quality nucleotides. Sequences were clustered into sub-operational taxonomic units (sOTUs,

179 hereafter called OTUs) following the deblur workflow (https://github.com/biocore/deblur) (Amir

180 et al., 2017). Sequences were trimmed to $150 \mathrm{bp}$ and OTUs with less than 10 reads were

181 excluded. The resulting OTUs were then assigned to a taxonomic group using the Greengenes

18213.8 reference database (May 2013 release; http://greengenes.lbl.gov/). Non-bacterial taxa (e.g.:

183 archaea, mitochondria and chloroplasts) were removed. All OTUs with less than $0.001 \%$ of the 
184 total reads of all analysed samples were excluded (Bokulich et al., 2013). PyNAST (Caporaso et 185 al., 2010) was used to align the OTU sequences and a phylogenetic tree was built with FastTree 186 (Price, Dehal, \& Arkin, 2010). Data was organized into three datasets: Dataset A included only 187 skin swabs from the two species; Dataset B included only skin swabs from males and females of 188 D. melanostictus; and Dataset C included only gut samples from the two species (Table S1).

189 Each dataset was rarefied to a specific number of reads per sample: Dataset A, B: 1,455; Dataset 190 C: 1,867 (Table S1). Dataset A was additionally rarefied at 4,000 reads/sample to allow a better 191 comparison with previous published works (e.g. Bletz et al., 2017a, Kueneman et al., 2019). 192 After filtering and rarefaction, the final dataset A included a total of 37 samples (S1: 9 D. 193 melanostictus, 4 P. mascareniensis; S2: 10 D. melanostictus, 3 P. mascareniensis; S3: 7 D. 194 melanostictus, 4 P. mascareniensis) with 1,617 OTUs for the skin bacteria dataset. Dataset B 195 included a total of 15 males $(\mathrm{S} 1=3, \mathrm{~S} 2=6, \mathrm{~S} 3=6)$ and 11 females $(\mathrm{S} 1=6, \mathrm{~S} 2=4$, S3=1) with the 196 female samples from S3 being excluded from the analysis (Table S2). Dataset C included 3 197 pooled samples for each species (each containing the gut of 4 individuals per species per site) 198 with 701 OTUs (Tables S1, S2).

\section{Statistical analysis}

200 Diversity indices and statistical analysis were performed using QIIME v1.9.1 and R 201 v3.4.4 (R Core Team, 2016). Data was organized into three datasets. Dataset A included a total 202 of 37 skin swabs from both species from all sites and was used to assess the effects of host and 203 site on skin bacteria; Dataset B included 26 skin swabs from D. melanostictus from all sites and 204 was used to assess the effect of sex on skin bacteria; Dataset $\mathrm{C}$ included six pooled (per species 205 and per site) gut samples and was used to assess the effects of host species on the gut bacteria 206 (Table S2 for more details).

Alpha diversity metrics were calculated to detect differences between host species, sexes 208 and sites. Species richness was measured as number of observed OTUs (OTU Richness) and Chao1 diversity index; and diversity was measured using Shannon diversity index and Faith's phylogenetic distance (PD). Significant differences between alpha indices were assessed using ANOVA (aov, stats package, R Core Team, 2016). For Dataset A, we used a two-way ANOVA, with factors "species", "site" and their interaction; for Dataset B, we used a one-way ANOVA, 213 with the factor "sex". In Dataset C, we used a non-parametric Kruskal-Wallis Test (KW) using 
214 the variable "species" although the low sample size does not allow for a robust statistical

215 analysis and values are indicative. Dissimilarity matrices were calculated using Weighted and

216 Unweighted Unifrac distances (Lozupone \& Knight, 2005) and visualized using a non-metric

217 multidimensional scaling plot (NMDS, phyloseq package, Mcmurdie \& Holmes, 2013).

218 Differences in the bacterial community structure (Beta Diversity) were analysed with

219 PERMANOVA (Adonis, vegan package, 999 permutations (Oksanen et al., 2016)) with species

220 and site as predictor variables, including main effects and their interaction. When significant

221 differences were observed, a test for homogeneity of groups dispersions was calculated using the

222 function betadisper in vegan package in $\mathrm{R}$ (Oksanen et al., 2016). Community composition was

223 visualized with bar plots including the most abundant taxa in each category (phylum, family and

224 genus) after transforming the counts into relative abundances and grouping all other taxa with

225 relative abundance lower than 1\% (Phylum from Dataset C), 5\% (Phylum from Datasets A and

226 B), 15\% (Family and Genus from Datasets A and B) and 10\% (Family and Genus from Dataset

227 C). An additional category "unidentified" represents the total relative abundance of taxa that

228 were not identified at that taxonomic level. Total shared and unique OTUs for each species were

229 represented as Venn diagrams for all groups using the collapsed biom tables retrieved from

230 QIIME. Since no significant differences were found between sites, the subsequent analysis was

231 performed with individuals from the three sites grouped together. Linear Discriminant Analysis

232 Effect Size (LEfSe) method (LDA score $>3.0, \alpha=0.05$ ) (Segata et al., 2011) was used to

233 determine OTUs responsible for the observed differences in the skin and gut communities

234 between species (Datasets A and C) and sexes (Dataset B). We used PICRUSt (Phylogenetic

235 Investigation of Communities by Reconstruction of Unobserved States) (Langille et al., 2013) to

236 gain a better understanding of the possible functions of the symbiotic bacteria identified in the

237 skin and in the gut. The OTUs were assigned to the Greengenes v13.5 database using the 97\%

238 similarity with the closed OTU-picking strategy, and a normalization of the copy numbers of

239 each OTU was performed. Subsequently, the metagenome of each sample was predicted, and a

240 functional categorization with respective abundances (following the Kyoto Encyclopedia of

241 Genes and Genomes - KEGG - Orthology database) performed, using level 2 KEGG Orthologs

242 (KO). Pathways with less than 10 counts were removed and abundances were rarefied. Both

243 LEfSe and PICRUSt analysis were run on the Galaxy Web platform

244 (http://huttenhower.sph.harvard.edu/galaxy). Significant differences between host species were 
245

246

247

248

249

250

251

252

253

254

255

256

257

258

259

260

261

262

263

264

265

266

267

268

269

270

271

272

273

assessed using the Kruskal-Wallis test (K-W) in QIIME. To better understand if the bacterial taxa could provide advantages regarding higher disease resistance in the toad, we mapped all skin bacterial OTUs (Datasets A and B) using a closed-reference OTU picking strategy, against the published database of antifungal amphibian skin bacterial isolates (Woodhams et al., 2015) this database includes isolates that are likely able to inhibit or enhance the growth of the amphibian fungal pathogen, Batrachochytrium dendrobatidis (Bd). Taxa with a match of $97 \%$ were retrieved and the proportions of OTUs with putative $B d$-inhibitory or $B d$-enhancing properties were calculated.

All applicable international, national and/or institutional guidelines for the care and use of animals were followed. Ministère de l'Environnement et du Développement Durable provide the research permits for: collection, $\mathrm{N}^{\circ} 226 / 16 / \mathrm{MEEF} / \mathrm{SG} / \mathrm{DGF} / \mathrm{DSAP} / \mathrm{SCB}$.Re of September 19th, 2016; transport, $\mathrm{N}^{\circ} 1679-16 / \mathrm{MEEF} / \mathrm{SG} / \mathrm{DGF} / \mathrm{DREEF} . \mathrm{ATS} / \mathrm{SREco}$ and $\mathrm{N}^{\circ} 1680$ 16/MEEF/SG/DGF/DREEF.ATS/SREco of September 24th, 2016; and export, N²84NEA10/MG16 of October 5th.

\section{Results}

\section{Dataset A - Comparison of the skin microbiome of Duttaphrynus melanostictus and} Ptychadena mascareniensis across the expansion range

Host species had a significant effect on alpha diversity indices of the cutaneous microbiome (Fig. 2A-D): D. melanostictus showed significantly higher values for OTU richness (ANOVA, $\mathrm{F}=33.15, \mathrm{p}<0.001$ ), phylogenetic diversity (ANOVA, $\mathrm{F}=40.66$, $\mathrm{p}<0.001$ ), Chao1 diversity (ANOVA, $\mathrm{F}=29.64, \mathrm{p}<0.001$ ) and Shannon diversity (ANOVA, $\mathrm{F}=7.289$, $\mathrm{p}=0.006$ ) compared to the native $P$. mascareniensis. Site did not have an effect on alpha diversity (ANOVA, OTUs: $\mathrm{F}=0.505, \mathrm{p}=0.61$; $\mathrm{PD}: \mathrm{F}=1.830, \mathrm{p}=0.180$; Chao1: $\mathrm{F}=1.274, \mathrm{p}=0.30$; Shannon:

$\mathrm{F}=1.074, \mathrm{p}=0.36$, SM Fig. S1A), and the interaction between species and site was not statistically significant (ANOVA, OTUs: $\mathrm{F}=0.729, \mathrm{p}=0.49$; $\mathrm{PD}$ : $\mathrm{F}=1.078, \mathrm{p}=0.35$; Chao1: $\mathrm{F}=0.334, \mathrm{p}=0.72$;

Shannon: $\mathrm{F}=0.783, \mathrm{p}=0.47$ ). However, a trend was observed with $D$. melanostictus showing greater values in all alpha indices across sites while $P$. mascareniensis showed an irregular pattern. 
Beta diversity significantly differed between host species when measured by both

275

276

277

278

279

280

281

282

283

284

285

286

287

288

289

290

291

292

293

294

295

296

297

298

299

300

301

302

303

weighted Unifrac (Fig. 2E, PERMANOVA: Pseudo- $\mathrm{F}_{(1,36)}=4.896, \mathrm{R}^{2}=0.118, \mathrm{p}=0.002$ ) and

unweighted Unifrac metrics (Fig. 2F, PERMANOVA: Pseudo- $F_{(1,36)}=6.565, R^{2}=0.156, p=0.001$ );

but did not differ across sites (Fig. 2E-F, PERMANOVA: weighted Pseudo- $\mathrm{F}_{(2,36)}=1.138$, $\mathrm{R}^{2}=0.055, \mathrm{p}=0.32$; unweighted Pseudo- $\left.\mathrm{F}_{(2,36)}=1.036, \mathrm{R}^{2}=0.049, \mathrm{p}=0.36\right)$. Similarly, the interaction of species and site did not affect beta diversity (Fig. 2E-F, PERMANOVA: weighted Pseudo- $\mathrm{F}_{(2,36)}=1.664, \mathrm{R}^{2}=0.080, \mathrm{p}=0.06$; unweighted Pseudo- $\left.\mathrm{F}_{(2,36)}=1.217, \mathrm{R}^{2}=0.058, \mathrm{p}=0.15\right)$. Analysis of dispersion indicated no significant differences between species (Weighted: $\mathrm{F}_{(1,35)}=0.863, \mathrm{p}=0.37$; Unweighted: $\mathrm{F}_{(1,35)}=1.996, \mathrm{p}=0.17$ ) or sites (Weighted: $\mathrm{F}_{(2,34)}=0.0649$, $\mathrm{p}=0.94$; Unweighted: $\left.\mathrm{F}_{(2,34)}=0.943, \mathrm{p}=0.40\right)$.

The skin bacterial communities from the two species were mainly composed of the same phyla (Actinobacteria, Bacteroidetes and Proteobacteria) but with several differences in relative abundances at lower taxonomic levels (family and genus; Fig. 2G-H). The D. melanostictus skin community had higher abundances of the families Alteromonadaceae, Comamonadaceae, Moraxellaceae and Sphingobacteriacae while the $P$. mascareniensis skin community had higher abundances of Enterobacteriaceae, Moraxellacaeae (only at Site 3), Pseudomonadaceae and Xanthomonadaceae. Notably, P. mascareniensis had a higher abundance of bacteria of the genus Pseudomonas while D. melanostictus had Cellvibrio as the most abundant genus. Across sites, the differences observed between host species were concordant. Within species, the patterns varied: $D$. melanostictus skin bacterial communities were more stable across sites and $P$. mascareniensis showed more variability in taxonomic abundance (Fig. 2G-H). LEfSe analysis revealed 39 taxa that were differently abundant in the two host species including 13 taxa that exhibited higher relative abundance in P. mascareniensis and 26 in D. melanosticus (Fig. 3). Specifically, P. mascareniensis only had differently abundant taxa from the phylum Proteobacteria and only one from the phylum Firmicutes, while D. melanostictus was characterized by significant differential abundance of taxa from the Actinobacteria, Proteobacteria, Bacteroidetes and Verrucomicrobia phyla. In P. mascarenienis, all differentially abundant taxa were included within the class Gammaproteobacteria with the exception of one Alphaproteobacteria taxon. In the case of $D$. melanostictus, differentially abundant bacteria belonged to several classes and families within different phyla (Fig. 3A).

PeerJ reviewing PDF | (2020:05:49550:2:0:NEW 22 Apr 2021) 
304

305

306

307

308

309

310

311

312

313

314

315

316

317

318

319

320

321

322

323

324

325

326

327

328

329

330

331

332

333

In total, D. melanostictus had more than 1,000 unique OTUs (equivalent to $80 \%$ of total number of OTUs) and shared only 238 (15\%) with P. mascareniensis, while the latter had only $5 \%$ unique OTUs (Fig. S1A). The percentage of shared OTUs between the species was similar at sites 1 and 3 and lower at site 2 (Fig. S1C). This lower percentage was coupled with higher number of unique OTUs found in the toad (Fig. S1C). Individuals of D. melanostictus across sites shared between $30-40 \%$ of OTUs, while the percentage of unique OTUs found at each site was around 20\% (Fig. S1B); individuals from sites 1 and 2 shared more OTUs than in comparison with the number of shared OTUs between each of the first two sites with site 3 (Fig. S1B). P. mascareniensis had similar trends, with individuals sharing a higher number of OTUs compared with the unique OTUs found at each site. However, the percentage of OTUs found at the three sites was only $9 \%$ (Fig. S1B).

A total of 39 KEGG pathways (Level 2) were predicted for the two amphibians'skin microbiomes, of which 18 exhibited significantly different relative abundance between species (Table S3). From these, D. melanostictus had 11 enriched functional groups including cell growth and death, transport and catabolism, biosynthesis of secondary metabolites, energy and lipid metabolism, xenobiotics biodegradation and environmental adaptation. P. mascareniensis had 7 enriched functional groups including membrane transport, infectious diseases, cellular processes and signalling, among others.

The two amphibians had significant differences in the proportion OTUs with putatively $B d$-inhibitory capacities but not in $B d$-enhancing skin OTUs (K-W: $\chi 2=11.5, \mathrm{p}<0.001$ and $\chi 2=3.10, \mathrm{p}=0.078$ respectively) with $P$. mascareniensis carrying higher proportions of putative $B d$-inhibitory OTUs (Fig. S3A).

\section{Dataset B - Comparison of the skin bacterial community of males and females of}

\section{Duttaphrynus melanostictus}

In terms of alpha diversity, Shannon was the only metric that was significantly different between the sexes (ANOVA: p=0.04, Fig. 4A-D). Beta diversity showed that sex was significant when assessing weighted Unifrac distances (PERMANOVA: Sex, Pseudo-F=2.35, $\mathrm{R}^{2}=0.09$, $\mathrm{p}=0.02$, Fig. 4E) but not with the Unweighted Unifrac distances (PERMANOVA: Sex, $\mathrm{p}>0.05$, Fig. 4F). Analysis of dispersion indicated a significant difference between sexes (Weighted Unifrac, $\left.\mathrm{F}_{(1,24)}=4.8089, \mathrm{p}=0.032\right)$. 
334

335

336

337

338

339

340

341

342

343

344

345

346

347

348

349

350

351

352

353

354

355

356

357

358

359

360

361

362

Males had higher abundances of Sphingobacteriacae and a high rate of unidentified taxa when compared with females (Fig. 4G-H). At the genus level, sex seemed to influence the abundance level of the most common taxa (Arthrobacter, Cellvibrio, Devosia) but without a clear pattern. Once again, males had a higher abundance of unidentified genus than females (Fig. 4G-H). However, LefSe analysis indicated that there were no differently abundant taxa.

Males had double the number of unique OTUs compared to females when samples from the three sites were grouped (Fig. S2). A total of 5 predicted KEGG pathways (Level 2) were more abundant in males and 4 in females (Table S4). Among these, females exhibited significantly higher abundances of functional groups associated with Immune System Diseases while males had higher abundances of functional groups associated to other diseases and associated to cellular processes (e.g., Transport and Catabolism) (Table S4).

Comparing the skin bacterial communities with the antifungal database showed marginal differences with males exhibiting a slightly higher proportion of putative $B d$-inhibitory skin OTUs (K-W: $\chi 2=3.59, \mathrm{p}=0.058)$. Both sexes exhibited similar proportions of putative $B d$ enhancing skin OTUs (K-W: $\chi 2=0.12, \mathrm{p}=0.74)$ (Fig. S3B).

\section{Dataset C - Comparison of gut bacterial communities of Duttaphrynus melanostictus and}

\section{Ptychadena mascareniensis}

In dataset $\mathrm{C}$, only one pooled sample (with four individuals each) per site and species was obtained, thus all the statistics were performed to compare only the effect of the host species (Fig. 5A-D). The complete plots with separated sites are available in supplementary material (Fig. S4A-D). The gut communities did not present significant differences in alpha diversity between host species for any of the indices (KW, OTUs: $\chi 2=2.33, \mathrm{df}=1, \mathrm{p}=0.13$; Chaol: $\chi 2=1.19$, $\mathrm{df}=1, \mathrm{p}=0.28$; PD: $\chi 2=1.19, \mathrm{df}=1, \mathrm{p}=0.28$; Shannon: $\chi 2=1.19, \mathrm{df}=1, \mathrm{p}=0.28$ ) although a trend for an increase in bacterial richness and diversity was observed in D. melanostictus (Fig. 5A-D; SM Fig. S4A).

No significant differences in gut community composition were found between the two species using both weighted Unifrac (PERMANOVA: Pseudo- $F_{1,5}=1.66 ; \mathrm{R}^{2}=0.3, \mathrm{p}=0.30$ ) and unweighted Unifrac (PERMANOVA: Pseudo- $\mathrm{F}_{1,5}=1.75 ; \mathrm{R}^{2}=0.3, \mathrm{p}=0.10$ ) distances (Fig. 5E-F, Fig. S4B). 
The gut community of both species was dominated by three phyla (Bacteroidetes,

364 Proteobacteria and Firmicutes) (Fig. 5G-H; Fig. S4C), with differences in the relative

365

366

367

368

369

370

371

372

373

374

375

376

377

378

379

380

381

382

383 abundances at lower taxonomic levels. D. melanostictus also exhibited high relative abundance of Fusobacteria. At the family level, D. melanostictus showed a more diverse gut community in terms of relative abundance including 10 families almost equally abundant (Fig. 5G-H), while $P$. mascareniensis had 7 families of high relative abundances, and among these, Clostridiaceae and Streptococcaceae were the most abundant. At the genus level, the gut community of $D$. melanostictus exhibited high abundance of Bacteroidetes and Cetobacterium while $P$. mascareniensis gut community was dominated by higher abundances of Clostridium and Lactococcus. Across sites, the gut communities of both amphibian' species also exhibited significant differences in terms of relative abundances of several taxa (Fig. S4C). With LefSe analysis, a total of 22 taxa were identified as being significantly more abundant in the gut of $D$. melanostictus, including members of the three phyla (Bacteroidetes, Firmicutes, Proteobacteria) while no taxa were enriched in P. mascareniensis (Fig. 6).

D. melanostictus had 365 unique OTUs (52\%), while P. mascareniensis had 256 (37\%) and only $11 \%$ of the bacterial OTUs (corresponding to a total of 80 OTUs) was shared (Fig. S5).

From the gut communities of the two species a total of 39 KEGG pathways (Level 2) were predicted, with both amphibians exhibiting the same functional groups. Significant differences in the abundance levels of these pathways were detected $(\mathrm{K}-\mathrm{W}, \mathrm{p}$-value $<0.05)$ (Table S5). D. melanostictus had 4 enriched functional groups: Biosynthesis of Secondary Metabolites, Energy Metabolism, Endocrine System and Information Processing - Folding, Sorting and Degradation, while P. mascareniensis had only one enriched functional group associated with membrane transport (Table S5).

\section{Discussion}

Our study provides the first characterization of the skin and gut microbiomes of the Asian common toad Duttaphrynus melanostictus in its invasive range in Madagascar occurring in a highly human impacted area, and includes a comparison with the co-occurring native species Ptychadena mascareniensis. To our knowledge, only five recent studies characterized the 
392 microbiome of an invasive amphibian: Christian et al. (2018) found that Rhinella marina had the

393 poorest and most dissimilar skin bacterial community in comparison with native amphibians in

394 Australia; Abarca et al. (2018) found, for the same species, higher skin bacterial diversity in

395 individuals from the invaded range compared to the native range; while, Kueneman et al. (2019)

396 found that on a global scale the skin microbiome of Lithobates catesbeianus was more similar to

397 that of the native amphibians than to itself in different parts of its invasive range. Two more

398 recent studies focused on the gut microbiome of invasive species. The first one characterized the

399 microbiome of $R$. marina while comparing the bacterial community across gut sections and

400 found that sex influenced the gut microbiota and that cloacal swabs can be a good proxy to study

401 intestinal microbes (Zhou et al., 2020). The second study found that the gut microbiome of the

402 invasive guttural toad (Sclerophrys gutturalis) exhibited greater microbial diversity and

403 functional flexibility when compared with bacterial communities from the native populations

404 (Wagener et al., 2020, unpublished work). We investigated a very recent invasion and aimed at

405 characterizing the microbiome of $D$. melanostictus across its expansion range and how it differs

406 from the microbiome of a native species from across three sites with similar levels of human

407 impact. Skin bacterial communities were strongly correlated with host species, with $D$.

408 melanostictus showing higher richness and diversity. At a lesser extent, sex also influenced these

409 communities. However, no significant differences in the skin bacterial composition were

410 observed between sampling sites for both species, which might be related to the small

411 geographic area and the overall similar habitat of the three sampling sites (all sampling sites

412 were urban areas). It also indicates that the skin microbiome of D. melanostictus individuals has

413 likely been stable across its recent expansion.

414

415

416

Skin bacteria diversity differs between the invasive toad $D$. melanostictus and the native frog $P$. mascareniensis but not across sites

417

The skin bacterial community of the two amphibian species differed in terms of richness,

418 diversity, community structure and functional inferences. D. melanostictus hosted a richer

419 community than the co-occurring native species, harboured many unique OTUs (80\%) and

420

average richness values similar to those found for other terrestrial species of amphibians in

421

Madagascar (Table S6; Bletz et al., 2017; Kueneman et al., 2019). On the other hand, the native

PeerJ reviewing PDF | (2020:05:49550:2:0:NEW 22 Apr 2021) 
422 species $P$. mascareniensis showed lower values of bacterial richness than the average values

423 found in previous studies comparing terrestrial or aquatic species from Madagascar (Table S6;

424 Bletz et al., 2017; Kueneman et al., 2019). However, previous studies mostly included terrestrial

425 amphibians (including P. mascarenienis) from multiple habitats (Bletz et al., 2017), while our

426 study included only urban sites around Toamasina. This habitat is characterized by high

427 anthropogenic pressures, such as the presence of cattle, human waste, no natural vegetation cover

428 and poor availability of clean water bodies, that can potentially have impoverished the

429 environmental bacterial pool and consequently reduce the richness of the bacterial communities

430 in P. mascareniensis but this should be further investigated in future assessments (Becker et al.,

431 2017; Jiménez et al., 2020).

432 Notably, D. melanostictus showed a dramatically higher percentage of unique OTUs

$433(80 \%)$ compared to the native species, which may be related with the toad skin characteristics

434 and therefore different skin microenvironment, and other host ecological factors. The percentage

435 of shared bacterial taxa $(15 \%)$ between our two species is low compared with what was observed

436 in previous works comparing different species (25-70\%), or between aquatic and terrestrial

437 ecomorphs or different life stages (Rebollar et al., 2016; Bletz et al., 2017; Kueneman et al.,

438 2014). Although not significant, we observed some variation in alpha diversity levels in the skin

439 microbiota of D. melanostictus in the three analysed sites. This could be linked to different

440 environmental bacteria colonizing the skin in each site. This was accompanied by higher

441 percentage of shared OTUs with P. mascareniensis which can also support the hypothesis that

442 the toad is being colonized by new environmental bacteria. To explain differences in bacterial

443 composition between the two target species, skin texture may also play a major role. Tubercles in

444 D. melanostictus skin may provide alternative microniches for the bacteria compared to the

445 smoother skin of P. mascareniensis. Moreover, the skin of amphibians has been suggested to

446 select and filter for specific bacteria from the surrounding environment due to the secretion of

447 skin compounds that may block colonization by some taxa and favour others, and this selection

448 could differ among host species (Flechas et al., 2019; Walke et al., 2014). Terrestrial amphibian

449 species (such as D. melanostictus) are expected to have richer skin communities than aquatic or

450 arboreal amphibians (Bletz et al., 2017; De Assis, Barreto, \& Navas, 2017; Kueneman et al.,

451 2019; Walke et al., 2014) partly because the soil usually harbours a richer bacterial pool than

452 aquatic systems and the habitat is known to greatly influence amphibians' skin communities. 
453 Although both species were found in the highly anthropized areas in Toamasina, $P$.

454 mascareniensis were mostly found in the grass and often close to small water-bodies, while 455 individuals of $D$. melanostictus were conspicuous within villages, sometimes near domestic 456 animals or anthropogenic waste.

457 So far, only a recent study attempted to assess the role of bacterial communities in the 458 adaptation of amphibians to novel habitats by studying the gut communities in invasive and 459 native populations (Wagener et al., 2020, unpublished data). In other systems, more diverse 460 microbiomes have been linked to higher host fitness, such as, for instance, pathogen resistance in 461 wheat (Matos, Kerkhof, \& Garland, 2005), or defence against chemical compounds in beetles 462 (Cheng et al., 2018). In amphibians, richer microbiomes have been linked to a higher resistance 463 to pathogens (Becker \& Harris, 2010; Harrison et al., 2017) and a richer microbiome could 464 conceivably aid in the colonization of novel habitats (Wagener et al., 2020, unpublished data). 465 Bacterial taxa associated with disease resistance were among the most abundant groups in both 466 hosts but with specific differences in taxa identity and abundances. P. mascareniensis seems to 467 carry a more diverse bacterial community with antifungal properties while the toad carried more 468 OTUs from the Comamonadaceae family that contains taxa used in probiotic assays (Becker et al., 2015). D. melanostictus also had very low abundance of Pseudomonas, a genus that is ubiquitous in the environment (soil, water), plants and other organisms and is linked to resistance to pathogens like $B d$ (Becker et al., 2015). Pseudomonas was highly prevalent in $P$.

472 mascareniensis and is usually abundant in amphibians from tropical regions (Bletz et al., 2017).

473 Notably, the low abundance of Pseudomonas found in D. melanostictus agrees with the pattern 474 found in invasive populations of $R$. marina: lower in invasive populations compared with native 475 ones (Abarca et al., 2018), and lower in comparison with co-occurring native amphibians from 476 Australia (Christian et al., 2018) and further analysis of this similarity should be applied.

The functional redundancy here observed was congruent with previous studies (Bletz et al., 2016; Huang et al., 2018), demonstrating that different microbiome assemblages from 479 different hosts can succeed in the same environment and are probably more associated with host 480 identity. From the host's perspective this is crucial since it means that it maintains functional stable microbial community despite carrying different bacterial assemblages. The functional 482 category of xenobiotics biodegradation and metabolism that was enriched in D. melanostictus 483 could be related with a high capacity to cope with environmental alteration and anthropogenic 
484 stress which would be the case in Toamasina, and therefore higher adaptability or resilience to 485 highly impacted or new habitats (Claus, Guillou, \& Ellero-Simatos, 2016). A future comparison 486 with individuals occurring in less human impacted areas could provide more insights regarding 487 the functional capacity of the microbiome in relation to the host habitat.

In a recent study with $R$. marina collected near its invasion front and where chytridiomycosis is absent, it was observed that individuals had lower $B d$-inhibitory bacteria when compared with areas where $B d$ was present, highlighting the hypothesis that these bacteria are selected when the pathogen is present (Weitzman et al., 2019). In the species analysed here, the lower proportion of bacteria with putative $B d$-inhibiting functions in $D$. melanostictus (in comparison with $P$. mascareniensis) may be related with its occurrence is Toamasina where $B d$ has not yet been detected (Bletz et al., 2015). However, it is important to note that the antifungal database include taxa isolated from amphibian species from Africa, America and Australia with no representatives from Asia, which can partially be responsible for the high proportion of taxa found in the native P. mascareniensis (Woodhams et al., 2015). Moreover, this classification is based on $97 \%$ similarity to bacteria that can inhibit $B d$ which does not necessarily mean that these bacteria actually have this function.

Moreover, D. melanostictus has been showed to have a high $B d$ prevalence (43\%) in its native areas in India (Thorpe et al., 2018), which may be linked to a low prevalence of $B d$ inhibitory bacteria, although it has not been tested there. A screen of the microbiome diversity of D. melanostictus from its native areas, and where $B d$ has been detected, could give new insights about microbiome patterns.

505

\section{Gut bacteria show no differentiation between the two species}

In gut bacterial communities some patterns were similar to skin communities. For example, D. melanostictus individuals hosted a bacterial gut community characterized by more unique OTUs and higher richness values (although not statistically significant). Although both species are generalist feeders (Döring et al., 2017; Fatroandrianjafinonjasolomiovazo et al.,

511 2011), P. mascareniensis feeds mainly on arthropods while the diet of $D$. melanostictus includes 512 other invertebrates and occasionally also small vertebrates (e.g. worm snakes) (Hahn, 1976;

513 O'Shea et al., 2013). A larger body size probably allows the consumption of larger and more 
514 diverse prey whereas the microhabitat type (soil, water, leaves) may also hold different

515 invertebrate groups influencing the potential prey availability for the two species. A richer

516 bacterial community has been related with richer diets probably aiding the host in the digestion

517 and metabolization of different items (Tiede et al., 2017, Wagener et al.2020, unpublished data).

518 The dominant bacterial phyla identified in the guts of the two amphibian species were similar to 519 other studies (Fig. 5c) (Chang et al., 2016; Huang et al., 2018), which might be explained by the 520 stable gut environment across species (compared for instance to the external environment). The

521 relative abundance of taxa, however, varied between the two species probably associated with

522 gut physiology, host diet and habitat conditions although the low sample size and the fact that the 523 samples were pooled is preventing us from obtaining robust comparisons (Ley et al., 2008; Tiede 524 et al., 2017; Zhang et al., 2010). Members of the phyla Firmicutes (mainly belonging to the class 525 Clostridia) are linked to fermentation of carbohydrates and found to be common in terrestrial 526 animals, thus its high occurrence in P. mascareniensis was expected. D. melanostictus has a 527 longer gut, and the lower oxygen availability associated with this environment (in addition to the 528 host's generalist diet), might explain the dominance of Bacteroidetes (Döring et al., 2017; Nelson 529 et al., 2013). Bacteroidetes can also assist in metabolizing different energy sources (Flint et al., 530 2012). The higher proportion of members of the family Desulfovibrionaceae in D. melanostictus 531 should be further studied since the group includes taxa that can be opportunist pathogens and 532 produce endotoxins (Zhang et al., 2010). The overall absence of significant differences between 533 the gut communities of these two species could also be the result of the low sample size used for 534 this dataset, even if each pool included a mix of gut samples from 4 individuals. Besides the lack 535 of significance in alpha and beta diversity, it is worth noting that we observed differences in the 536 relative abundance levels, number of unique OTUs and functional inference, but further 537 investigation is needed in this respect.

538

539 Conclusions

540 The expansion of the Asian common toad Duttaphrynus melanostictus in Madagascar is 541 ongoing and comparing the recently introduced populations across its invaded range and 542 subsequently expansion into different habitat types could help understand how microbiome 543 changes through the process of invasion in a contemporary scenario. Our study show that the 
544 skin microbiome of $D$. melanostictus is richer and more diverse than the skin microbiome of the

545 native species, and this diversity is probably associated with the toad intrinsic physiological and

546 ecological traits (e.g. the toad's skin microenvironment), or can be linked to the colonization of

547 new areas, with the toad being less likely to be selecting for any specific taxa. Expanding this

548 study to other native amphibian species and other habitats (following Licata et al. 2020, the toad

549 is currently occupying urban, rural/agricultural, palm-oil plantation and savoka (degraded forest

550 and mixed scrubland) habitats) is needed to further understand these differences. Additional data

551 from its natural range in Asia and from other invasive populations could help to better

552 characterize the degree of variation between native and invasive populations. For Madagascar,

553 we encourage the development of new studies aimed at characterizing skin secretions and the

554 antifungal properties of the skin microbiome of D. melanostictus. Similarly, we think that it will

555 be beneficial to further investigate the connection between the toad's diet and its gut microbiome

556 (composition and functional roles), especially in this invasion scenario where the host may have

557 to adapt fast as it will expand to different areas in Madagascar (colonization of different

558 habitats).

\section{Ethical Approval}

560 All applicable international, national and/or institutional guidelines for the care and use of

561 animals were followed. Samples were collected under research permit

$562 \mathrm{~N}^{\circ} 226 / 16 / \mathrm{MEEF} / \mathrm{SG} / \mathrm{DGF} / \mathrm{DSAP} / \mathrm{SCB}$.Re of September 19 ${ }^{\text {th }}, 2016$, transported under permits

$563 \quad \mathrm{~N}^{\circ} 1679-16 / \mathrm{MEEF} / \mathrm{SG} / \mathrm{DGF} / \mathrm{DREEF} . \mathrm{ATS} / \mathrm{SREco}$ and $\mathrm{N}^{\circ} 1680$ -

564 16/MEEF/SG/DGF/DREEF.ATS/SREco of September 24 $4^{\text {th }}, 2016$ and exported with permit

$565 \mathrm{~N}^{\circ} 284 \mathrm{~N}-\mathrm{EA} 10 / \mathrm{MG} 16$ of October $5^{\text {th }}, 2016$.

566

567 References

568 Abarca JG, Zuniga I, Ortiz-Morales G, Lugo A, Viquez-Cervilla M, Rodriguez-Hernandez N, 569 Vázquez-Sánchez F, Murillo-Cruz C, Torres-Rivera EA, Pinto-Tomás AA, Godoy-Vitorino F. 570 2018. Characterization of the skin microbiota of the cane toad Rhinella cf. marina in Puerto Rico 571 and Costa Rica. Frontiers in Microbiology 8(2624):1-13 DOI:10.3389/fmicb.2017.02624 
572 Abdallah F, Mijouin L, \& Pichon C. (2017). Skin immune landscape: inside and outside the

573 organism. Mediators of Inflammation 5095293: 1-17 DOI:10.1155/2017/5095293

574 Alpert P, Bone E, \& Holzapfel C. (2000). Invasiveness, invasibility and the role of

575 environmental stress in the spread of non-native plants. Perspectives in Plant Ecology, Evolution

576 and Systematics 3(1):52-66 DOI:10.1078/1433-8319-00004

577 Amir A, McDonald D, Navas-Molina JA, Kopylova E, Morton JT, Xu ZZ, Kightley EP,

578 Thompson LR, Hyde ER, Gonzalez A, Knight R. 2017. Deblur rapidly resolves single-nucleotide

579 community sequence patterns. American Society for Microbiology 2(2):1-7

580 DOI:10.1128/mSystems.00191-16.

581 Andreone F, Rabibisoa N, Randrianantoandro C, Crottini A, Edmonds D, Kraus F, Lewis JP,

582 Moore M, Rabemananjara FCE, Rabemanantsoa JC, Vences M. 2014. Risk review is under way

583 for invasive toad. Nature 512(7514), 253 DOI:10.1038/512253d

584 Beard KH, Pitt WC. 2005. Potential consequences of the coqui frog invasion in Hawaii.

585 Diversity and Distributions 11(5): 427-433 DOI:10.1111/j.1366-9516.2005.00178.x

586 Becker MH, Harris RN. 2010. Cutaneous bacteria of the redback salamander prevent morbidity

587 associated with a lethal disease. PLoS ONE 5(6):1-6. DOI:10.1371/journal.pone.0010957

588 Becker MH, Walke JB, Murrill L, Woodhams DC, Reinert LK, Rollins-Smith LA, Burzynski

589 EA, Umile TP, Minbiole KPC, Belden LK. 2015. Phylogenetic distribution of symbiotic bacteria

590 from Panamanian amphibians that inhibit growth of the lethal fungal pathogen Batrachochytrium

591 dendrobatidis. Molecular Ecology 24(7):1628-1641 DOI:10.1111/mec.13135

592 Becker CG, Longo AV, Haddad CFB, Zamudio KR. 2017. Land cover and forest connectivity 593 alter the interactions among host, pathogen and skin microbiome. Proceedings of the Royal

594 Society B: Biological Sciences 284:20170582 DOI: 10.1098/rspb.2017.0582

595 Bletz MC, Archer H, Harris RN, McKenzie VJ, Rabemananjara FC, Rakotoarison A, Vences M.

596 2017. Host ecology rather than host phylogeny drives amphibian skin microbial community

597 structure in the biodiversity hotspot of Madagascar. Frontiers in Microbiology 8(1530):1-14.

598 DOI:10.3389/fmicb.2017.01530 
599 Bletz MC, Goedbloed DJ, Sanchez E, Reinhardt T, Tebbe CC, Bhuju S, Geffers R, Jarek M, 600 Vences M, Steinfartz, S. 2016. Amphibian gut microbiota shifts differentially in community 601 structure but converges in habitat-specific predicted functions. Nature Communications 602 7(13699):1-12 DOI:10.1038/ncomms13699

603 Bletz MC, Perl RGB, Vences M. 2017. Skin microbiota differs drastically between co-occurring 604 frogs and newts. Royal Society Open Science 4(4):170107 DOI:10.1098/rsos. 170107

605 Bletz MC, Rosa GM, Andreone F, Courtois EA, Schmeller DS, Rabibisoa NH, Rabemananjara 606 FCE, Raharivololoniaina L, Vences M, Weldon C, Edmonds D, Raxworthy CJ, Harris RN, 607 Fisher MC, Crottini A. 2015. Widespread presence of the pathogenic fungus Batrachochytrium 608 dendrobatidis in wild amphibian communities in Madagascar. Scientific Reports 5(8633):1-10 609 DOI:10.1038/srep08633

610 Bokulich NA, Subramanian S, Faith JJ, Gevers D, Gordon JI, Knight R, Mills DA, Caporaso JG. 611 2013. Quality-filtering vastly improves diversity estimates from Illumina amplicon sequencing. 612 Nature Methods 10(1):57-59 DOI:10.1038/nmeth.2276

613 Brown JL, Sillero N, Glaw F, Bora P, Vieites DR, Vences M. 2016. Spatial biodiversity patterns 614 of Madagascar's amphibians and reptiles. PLoS ONE 11(1):1-26

615 DOI:10.1371/journal.pone.0144076

616 Caporaso JG, Bittinger K, Bushman FD, SeSantis TZ, Andersen GL, Knight R. 2010. PyNAST: 617 A flexible tool for aligning sequences to a template alignment. Bioinformatics 26(2):266-267 618 DOI:10.1093/bioinformatics/btp636

619 Caporaso JG, Kuczynski J, Stombaugh J, Bittinger K, Bushman FD, Costello EK, Fierer N, Peña 620 AG, Goodrich JK, Gordon JI, Huttley GA, Kelley ST, Knights D, Koenig JE, Ley RE, Lozupone 621 CA, McDonald D, Muegge BD, Pirrung M, Reeder J, Sevinsky JR, Turnbaugh PJ, Walters WA, 622 Widmann J, Yatsunenko T, Zaneveld J, Knight R. 2010. QIIME allows analysis of high623 throughput community sequencing data Intensity normalization improves color calling in SOLiD 624 sequencing. Nature Publishing Group 7(5):335-336 DOI:10.1038/nmeth0510-335 
625 Caporaso JG, Lauber CL, Walters WA, Berg-Lyons D, Lozupone CA, Turnbaugh PJ, Fierer N, 626 Knight R. 2012. Global patterns of 16S rRNA diversity at a depth of millions of sequences per 627 sample. PNAS 108:4516-4522 DOI:10.1073/pnas.1000080107

628 Chang CW, Huang BH, Lin SM, Huang CL, Liao PC. 2016. Changes of diet and dominant 629 intestinal microbes in farmland frogs. BMC Microbiology 16(1):1-13 DOI:10.1186/s12866-016$630 \quad 0660-4$

631 Cheng C, Wickham JD, Chen L, Xu D, Lu M, Sun J. 2018. Bacterial microbiota protects an 632 invasive bark beetle from a pine defensive compound. Microbiome 6(1):132 633 DOI:10.1186/s40168-018-0518-0

634 Chornesky EA, Randall JM. 2003. The threat of invasive alien species to biological diversity: 635 setting a future course. Annals of the Missouri Botanical Garden 90(1):67 DOI:10.2307/3298527

636 Christian K, Weitzman C, Rose A, Kaestli M, Gibb K. 2018. Ecological patterns in the skin 637 microbiota of frogs from tropical Australia. Ecology and Evolution 8(21):10510-10519 638 DOI:10.1002/ece3.4518

639 Claus SP, Guillou H, Ellero-Simatos S. 2016. The gut microbiota: A major player in the toxicity 640 of environmental pollutants? Npj Biofilms and Microbiomes 2(16003):1-12

641 DOI:10.1038/npjbiofilms.2016.3

642 Coats VC, Rumpho ME. 2014. The rhizosphere microbiota of plant invaders: an overview of 643 recent advances in the microbiomics of invasive plants. Frontiers in Microbiology 5(368):1-10 644 DOI:10.3389/fmicb.2014.00368

645 Crooks JA, Chang AL, Ruiz GM. 2011. Aquatic pollution increases the relative success of 646 invasive species. Biological Invasions 13(1):165-176 DOI:10.1007/s10530-010-9799-3

647 Crottini A, Andreone F, Edmonds D, Hansen CM, Lewis,JP, Rabemanantsoa JC, Moore M, 648 Kraus F, Vences M, Rabemananjara F, Randrianantoandro C. 2014. A new challenge for 649 amphibian conservation in Madagascar: the invasion of Duttaphrynus melanostictus in 650 Toamasina Province. FrogLog 22 (3)(111):46-47 
651 De Assis AB, Barreto CC, Navas CA. 2017. Skin microbiota in frogs from the Brazilian Atlantic 652 Forest: Species, forest type, and potential against pathogens. PLoS ONE 12(7):e0179628

653 DOI:10.1371/journal.pone.0179628

654 Dethlefsen L, Mcfall-Ngai M, Relman DA. 2007. An ecological and evolutionary perspective on 655 human - microbe mutualism and disease. Nature 449(7164):811-818 DOI:10.1038/nature06245

656 Döring B, Mecke S, Kieckbusch M, O’Shea M, Kaiser H. 2017. Food spectrum analysis of the 657 Asian toad, Duttaphrynus melanostictus (Schneider, 1799) (Anura: Bufonidae), from Timor 658 Island, Wallacea. Journal of Natural History 51(11-12):1-17

659 DOI:10.1080/00222933.2017.1293182

660 Enserink M. 1999. Predicting invasions: biological invaders sweep in. Science 285(5435):18346611836 DOI:10.1126/science.285.5435.1834

662 Fatroandrianjafinonjasolomiovazo TNL, Rasiamampionona NR, Vieites DR, Vences M. 2011. 663 Diet of the Mascarene grass frog, Ptychadena mascareniensis, in Madasgacar. Malagasy Nature $664 \quad 5: 68-74$

665 Flechas SV, Acosta-González A, Escobar LA, Kueneman JG, Sánchez-Quitian ZA, Parra666 Giraldo CM, Rollins-Smith LA, Reinert LK, Vredenburg VT, Amézquita A, Woodhams, DC. 667 2019. Microbiota and skin defense peptides may facilitate coexistence of two sympatric Andean 668 frog species with a lethal pathogen. The ISME Journal 13:361-373 DOI:10.1038/s41396-018$669 \quad 0284-9$

670 Flint HJ, Scott KP, Duncan SH, Louis P, Forano E. 2012. Microbial degradation of complex 671 carbohydrates in the gut. Gut Microbes 3(4):289-306 DOI:10.4161/gmic.19897

672 Ganzhorn JU, Lowry PP, Schatz GE, Sommer S. 2001. The biodiversity of Madagascar: one of 673 the world's hottest hotspots on its way out. Oryx 35(4):346-348 DOI:10.1046/j.1365$674 \quad 3008.2001 .00201 . x$

675 Garg AD, Kanitkar D, Hippargi R, Gandhare AN. 2007. Antimicrobial activity of skin secretions 676 isolated from Indian toad, Bufo melanostictus Schneider 1799. Nature Precedings 1-8

677 DOI:10.1038/npre.2007.1204.1 
678 Goodman SM, Raselimanana AP, Andriniaina HA, Gauthier N, Ravaojanahary F, Sylvestre M, 679 Raherilalao M. 2017. The distribution and ecology of invasive alien vertebrate species in the 680 greater Toamasina region, central eastern Madagascar. Malagasy Nature 12:95-109

681 Gribben PE, Nielsen S, Seymour JR, Bradley DJ, West MN, Thomas T. 2017. Microbial 682 communities in marine sediments modify success of an invasive macrophyte. Scientific Reports 683 7(9845):1-8 DOI:10.1038/s41598-017-10231-2

684 Grice E. 2014. The skin microbiome: potential for novel diagnostic and therapeutic approaches 685 to cutaneous disease. Seminars in Cutaneous Medicine and Surgery 33(2):98-103 686 DOI:10.12788/j.sder.0087

687 Grice EA, Segre JA. 2012. The human microbiome: our second genome. Annual Review of 688 Genomics and Human Genetics 13(1):151-170 DOI:10.1146/annurev-genom-090711-163814 689 Hahn DE. 1976. Worm snakes in the diet of a toad, Bufo Melanostictus. Herpetological Review $6907(4)$.

691 Harper GJ, Steininger MK, Tucker CJ, Juhn D, Hawkins F. 2007. Fifty years of deforestation 692 and forest fragmentation in Madagascar. Environmental Conservation 34(4):325-333 693 DOI:10.1017/S0376892907004262

694 Harrison XA, Price SJ, Hopkins K, Leung WTM, Sergeant C, Garner T. 2017. Host microbiome 695 richness predicts resistance to disturbance by pathogenic infection in a vertebrate host. BioRxiv 696 158428. doi:10.1101/158428

697 Heijitx RD, WangS, Anuar F, Qian Y, Björkholm B, Samuelsson A, Hibberd ML, Forssberg H, 698 Pettersson S. 2011. Normal gut microbiota modulates brain development and behavior. PNAS 699 108(7):1-6 DOI:10.1073/pnas.1010529108

700 Huang B-H, Chang C, Huang C, Gao J, Liao P-C. 2018. Composition and functional specialists 701 of the gut microbiota of frogs reflect habitat differences and agricultural activity. Frontiers in 702 Microbiology 8:1-14 DOI:10.3389/fmicb.2017.02670

703 Jani AJ, Briggs CJ. 2018. Host and aquatic environment shape the amphibian skin microbiome 704 but effects on downstream resistance to the pathogen Batrachochytrium dendrobatidis are 705 variable. Frontiers in Microbiology 9(487):1-17 DOI:10.3389/fmicb.2018.00487 
706 Jiménez RR, Alvarado G, Sandoval J, Sommer S. 2020. Habitat disturbances influences the skin

707 microbiome of a rediscovered neotropical-montane frog. BMC Microbiology 20:292. DOI:

708 10.1186/s12866-020-01979-1.

709 Kolby JE. 2014. Stop Madagascar's toad invasion now. Nature 509(7502):563-563

710 DOI:10.1038/509563a

711 Konrad M, Grasse AV, Tragust S, Cremer S. 2014. Anti-pathogen protection versus survival 712 costs mediated by an ectosymbiont in an ant host. Proceedings of the Royal Society B: Biological 713 Sciences 282(1799):20141976 DOI:10.1098/rspb.2014.1976

714 Kozich JJ, Westcott SL, Baxter NT, Highlander SK, Schloss, PD. 2013. Development of a dual715 index sequencing strategy and curation pipeline for analyzing amplicon sequence data on the 716 miseq illumina sequencing platform. Applied and Environmental Microbiology 79(17):5112717 5120 DOI:10.1128/AEM.01043-13

718 Kueneman JG, Bletz MC, Mckenzie VJ, Becker CG, Joseph MB, Abarca JG, Archer H, Arellano 719 AL, Bataille A, Becker M, Belden LK, Crottini A, Geffers R, Haddad CFB, Harris RN, Holden 720 WM, Hughey M, Jarek M, Kearns PJ, Kerby JL, Kielgast J, Kurabayashi A, Longo AV, Loudon 721 A, Medina D, Nuñez JJ, Perl RGB, Pinto-Tomás A, Rabemananjara FCE, Rebollar EA, Rodrígez 722 A, Rollins-Smith L, Stevenson R, Tebbe CC, Asensio GV, Waldman B, Walke JB, Whitfield 723 SM, Zamudio KR, Chaves IB, Woodhams DC, Vences M. 2019. Community richness of 724 amphibian skin bacteria correlates with bioclimate at the global scale. Nature Ecology \& 725 Evolution 3:381-389 DOI:10.1038/s41559-019-0798-1

726 Kueneman JG, Parfrey LW, Woodhams DC, Archer HM, Knight R, McKenzie V. 2014. The 727 amphibian skin-associated microbiome across species, space and life history stages. Molecular 728 Ecology 23(6):1238-1250 DOI:10.1111/mec.12510

729 Kull C, Tassin J, Carriere S. 2015. Approaching invasive species in Madagascar. Madagascar 730 Conservation \& Development 9(2):60 DOI:10.4314/mcd.v9i2.2

731 Kwon S, Park S, Lee B, Yoon S. 2013. In-depth analysis of interrelation between quality scores 732 and real errors in illumina reads. In 2013 35th Annual International Conference of the IEEE 
733 Engineering in Medicine and Biology Society (EMBC) (pp. 635-638)

734 DOI:10.1109/EMBC.2013.6609580

735 Langille MGI, Zaneveld J, Caporaso JG, McDonald D, Knights D, Reyes JA, Clemente JC,

736 Burkepile DE, Thurber RLV, Knight R, Beiko RG, Huttenhower C. 2013. Predictive functional

737 profiling of microbial communities using 16S rRNA marker gene sequences. Nature

738 Biotechnology 31(9):814-821 DOI:10.1038/nbt.2676

739 Lester PJ, Sébastien A, Suarez AV, Barbieri RF, Gruber MAM. 2017. Symbiotic bacterial

740 communities in ants are modified by invasion pathway bottlenecks and alter host behavior.

741 Ecology 98(3):861-874 DOI:10.1002/ecy.1714

742 Ley RE, Hamady M, Lozupone C, Turnbaugh PJ, Ramey RR, Bircher JS, Schlegel ML, Tucker

743 TA, Schrenzel MD, Knight R, Gordon JI. 2008. Evolution of mammals and their gut microbes.

744 Science 320(5883):1647-1651 DOI:10.1126/science.1155725

745 Licata F, Ficetola GF, Freeman K, Mahasoa RH, Ravololonarivo V, Solofo Niaina Fidy JF, 746 Koto-Jean AB, Nahavitatsara ER, Andreaone F, Crottini A. 2019. Abundance, distribution and 747 spread of the invasive Asian toad Duttaphrynus melanostictus in eastern Madagascar. Biological 748 Invasions 21(5):1615-1626 DOI:10.1007/s10530-019-01920-2

749 Licata F, Andreone F, Freeman K, Rabesihanaka S, Robsomanitrandrasana E, Reardon J, 750 Crottini A. 2020: The Asian Toad (Duttaphrynus melanostictus) in Madagascar: A Report of an 751 Ongoing Invasion. - In: F.M. Angelici, L. Rossi (Eds): Problematic Wildlife II, New

752 Conservation and Management Challenges in the Human-Wildlife Interactions, pp: 617-638.

753 Springer, Berlin, Germany.

754 Lowe S, Browne M, Boudjelas S, De Poorter M. 2000. 100 of the World's Worst Invasive Alien 755 Species. A selection from the Global Invasive Species Database. Published by The Invasive 756 Species Specialist Group (ISSG) a specialist group of the Species Survival Commission (SSC) of 757 the World Conservation Union.

758 Lozupone C, Knight R. 2005. UniFrac: a new phylogenetic method for comparing microbial 759 communities. Applied and Environmental Microbiology 71(12):8228-8235

760 DOI:10.1128/AEM.71.12.8228 
761 Marshall BM, Casewell NR, Vences M, Glaw F, Andreone F, Rakotoarison A, Zancolli G,

762 Woog F, Wüster W. 2018. Vulnerability of Malagasy predators to the toxins of an introduced 763 toad. Current Biology 28(11):R654-R655 DOI:10.1016/j.cub.2018.04.024

764 Matos A, Kerkhof L, Garland J. 2005. Effects of microbial community diversity on the survival 765 of Pseudomonas aeruginosa in the wheat rhizosphere. Microbial Ecology 49(2):257-264 766 DOI:10.1007/s00248-004-0179-3

767 McKenzie VJ, Bowers RM, Fierer N, Knight R, Lauber CL. 2012. Co-habiting amphibian 768 species harbor unique skin bacterial communities in wild populations. The ISME Journal 1-9 769 DOI:10.1038/ismej.2011.129

770 McMurdie PJ, Holmes S. 2013. phyloseq: An R package for reproducible interactive analysis 771 and graphics of microbiome census data. PLoS One 8 DOI:10.1371/journal.pone.0061217

772 Miaud C, Pozet F, Gaundin NCG, Mantel A, Pasmans F, Labrut S. 2016. Ranavirus causes mass 773 die-offs of the Alpine amphibians in the southwestern Alps (France). Journal of Wildlife 774 Diseases 52(2):242-252 DOI:10.7589/2015-05-113

775 Moore M, Niaina Fidy JFS, Edmonds D. 2015. The new toad in town: Distribution of the Asian 776 toad, Duttaphrynus melanostictus, in the Toamasina area of eastern Madagascar. Tropical 777 Conservation Science 8(2):440-455 DOI:10.1177/194008291500800210

778 Nelson TM, Rogers TL, Carlini AR, Brown MV. 2013. Diet and phylogeny shape the gut 779 microbiota of Antarctic seals: a comparison of wild and captive animals. Environmental 780 Microbiology 15(4):1132-1145 DOI:10.1111/1462-2920.12022

781 O’Shea M, Kathriner A, Mecke S, Sanchez C, Kaiser H. 2013. "Fantastic Voyage": a live 782 blindsnake (Ramphotyphlops braminus) journeys through the gastrointestinal system of a toad 783 (Duttaphrynus melanostictus). Herpetological Notes 6:467-470

784 Oksanen J, Blanchet F, Friendly M, Kindt R, Legendre P, McGlinn D, Minchin PR, O’Hara RB, 785 Simpson GL, Solymos P, Stevens MHH, Szoecs E, Wagner H. 2016. vegan: Community 786 Ecology Package. R package version 2.4-3. 
787 Penk MR, Jeschke JM, Minchin D, Donohue I. 2016. Warming can enhance invasion success

788 through asymmetries in energetic performance. Journal of Animal Ecology 85(2):419-426

789 DOI:10.1111/1365-2656.12480

790 Perl RGB, Vences M, Wollenberg KC, Sonet G, Glaw F, Nagy ZT. 2014. DNA barcoding

791 Madagascar's amphibian fauna. Amphibia-Reptilia 35(2):197-206 DOI:10.1163/15685381-

79200002942

793 Phillips BL, Brown GP, Webb JK, Shine R. 2006 Invasion and the evolution of speed in toads.

794 Nature 439(7078):803

795 Pitt W, Vice D, Pitzler M. 2005. Challenges of invasive reptiles and amphibians. Proceedings of

796 the 11th Wildlife Damage Management Conference, 112-119.

797 Price MN, Dehal PS, Arkin AP. 2010. FastTree 2 - approximately maximum-likelihood trees for 798 large alignments. PLoS ONE 5(3):e9490 DOI:10.1371/journal.pone.0009490

799 R Core Team. 2016. R: A language and environment for statistical computing. Vienna, Austria:

800 Foundation for Statistical Computing.

801 Rebollar EA, Hughey MC, Medina D, Harris RN, Ibáñez R, Belden LK. 2016. Skin bacterial

802 diversity of Panamanian frogs is associated with host susceptibility and presence of

803 Batrachochytrium dendrobatidis. ISME Journal 1-14 DOI:10.1038/ismej.2015.234

804 Reilly SB, Wogan GO, Stubbs AL, Arida E, Iskandar DT, McGuire JA. 2017. Toxic toad 805 invasion of Wallacea: a biodiversity hotspot characterized by extraordinary endemism. Global

806 Change Biology 23(12):5029-5031 DOI:10.1111/ijlh.12426

807 Rosa GM, Andreone F, Crottini A, Hauswaldt JS, Noël J, Rabibisoa NH, Randriambahiniarime

808 MO, Rebelo R, Raxworthy CJ. 2012. The amphibians of the relict Betampona low-elevation

809 rainforest, eastern Madagascar: An application of the integrative taxonomy approach to

810 biodiversity assessments. Biodiversity and Conservation 21(6):1531-1559 DOI:10.1007/s10531-

811 012-0262-x

812 Rout ME, Chrzanowski TH, Westlie TK, DeLuca TH, Callaway RM, Holben WE. 2013.

813 Bacterial endophytes enhance competition by invasive plants. American Journal of Botany

814 100(9):1726-1737 DOI:10.3732/ajb.1200577 
815 Sanford JA, Gallo RL. 2013. Functions of the skin microbiota in health and disease. Seminars in 816 Immunology 25(5):370-377 DOI:10.1016/j.smim.2013.09.005

817 Schlaepfer MA, Sax DF, Olden JD. 2011. The potential conservation value of non-native 818 species. Conservation Biology 25(3):428-437 DOI:10.1111/j.1523-1739.2010.01646.x

819 Segata N, Izard J, Waldron L, Gevers D, Miropolsky L, Garrett WS, Huttenhower C. 2011.

820 Metagenomic biomarker discovery and explanation. Genome Biology 12(6):R60

821 DOI:10.1186/gb-2011-12-6-r60

822 Shine R. 2010. The ecological impact of invasive cane toads (Bufo marinus) in Australia. The 823 Quarterly Review of Biology 85(3):253-291 DOI:10.1086/655116

824 Snow NP, Witmer GW. 2010. American bullfrogs as invasive species: a review of the 825 introduction, subsequent problems, management options, and future directions. USDA National 826 Wildlife Research Center - Staff Publications, 1288, 86-89.

827 Stachowicz JJ, Terwin JR, Whitlatch RB, Osman RW. 2002. Linking climate change and 828 biological invasions: Ocean warming facilitates nonindigenous species invasions. PNAS 829 99(24):15497-15500 DOI:10.1073?pnas.242437499

830 Thorpe CJ, Lewis TR, Fisher MC, Wierzbicki CJ, Kulkarni S, Pryce D, Davies L, Watve A, 831 Knight ME. 2018. Climate structuring of Batrachochytrium dendrobatidis infection in the 832 threatened amphibians of the northern western Ghats, India. Royal Society Open Science 5(6): 833 180211 DOI:10.1098/rsos.180211

834 Tiede J, Scherber C, Mutschler J, McMahon KD, Gratton C. 2017. Gut microbiomes of mobile 835 predators vary with landscape context and species identity. Ecology and Evolution 7(20):85458368557 DOI:10.1002/ece3.3390

837 Tuddenham S, Sears CL. 2015. The intestinal microbiome and health. Current Opinion in 838 Infection Diseases 28(5):464-470 DOI:10.1097/QCO.0000000000000196

839 Turnbaugh P, Ley R, Mahowald M, Magrini V, Mardis E, Gordon J. 2006. An obesity-associated 840 gut microbiome with increased capacity for energy harvest. Nature 444(7122):1027-1031

841 DOI:10.1038/nature05414 
842 Vences M, Brown JL, Lathrop A, Rosa GM, Cameron A, Crottini A, Dolch R, Edmonds D, 843 Freeman KLM, Glaw F, Grismer LL, Litvinchuk S, Milne MG, Moore M, Solofo JF, Noël J, 844 Nguyen TQ, Ohler A, Randrianantoandro C, Raselimanana AP, Leeuwen P van, Wogan GOU, 845 Ziegler T, Andreone F, Murphy RW. 2017. Tracing a toad invasion: Lack of mitochondrial DNA 846 variation, haplotype origins, and potential distribution of introduced Duttaphrynus melanostictus 847 in Madagascar. Amphibia-Reptilia 38(2):197-207 DOI:10.1163/15685381-00003104

848 Vieites DR, Wollenberg KC, Andreone F, Kohler J, Glaw F, Vences M. 2009. Vast 849 underestimation of Madagascar's biodiversity evidenced by an integrative amphibian inventory. 850 Proceedings of the National Academy of Sciences 106(20):8267-8272

851 DOI:10.1073/pnas.0810821106

852 Walke JB, Becker MH, Loftus SC, House LL, Cormier G, Jensen RV, Belden LK. 2014. 853 Amphibian skin may select for rare environmental microbes. The ISME Journal 8(11):22078542217 DOI:10.1038/ismej.2014.77

855 Walther G-R, Roques A, Hulme PE, Sykes MT, Pyšek P, Kühn I, Zobel M, Bacher S, Botta856 Dukát Z, Bugmann H, Czúcz B, Dauber J, Hickler T, Jarosík V, Kenis M, Klotz S, Minchin D, 857 Moora M, Nentwig W, Ott J, Panov VE, Reineking B, Robinet C, Semenchenko V, Solarz W, 858 Thuiller W, Vilà M, Vohland K, Settele J. 2009. Alien species in a warmer world: risks and 859 opportunities. Trends in Ecology \& Evolution 24(12):686-693 DOI:10.1016/j.tree.2009.06.008

860 Weitzman CL, Kaestli M, Gibb K, Brown GP, Shine R, Christian K. 2019. Disease exposure and 861 antifungal bacteria on skin of invasive Cane toads, Australia. Emerging Infectious Diseases 862 25(9):1770-1771

863 Woodhams DC, Alford RA, Antwis RE, Archer H, Becker MH, Belden LK, Bell CA, Bletz M, 864 Daskin JH, Davis LR, Flechas SV, Lauer A, Gonzalez A, Harris RN, Holden WM, Hughey MC, 865 Ibáñez R, Knight R, Kueneman J, Rabemananjara F, Reinert LK, Rollins-Smith LA, Roman866 Rodriguéz F, Shaw SD, Walke JB, Mckenzie VJ. 2015. Antifungal isolates database of 867 amphibian skin-associated bacteria and function against emerging fungal pathogens. Ecology 868 96(2):595 
869 Xavier R, Mazzei R, Pérez-Losada M, Rosado D, Santos JL, Veríssimo A, Soares MC. 2019. A 870 risky business? Habitat and social behavior impact skin and gut microbiomes in Caribbean

871 cleaning gobies. Frontiers in Microbiology 10:1-9 DOI:10.3389/fmicb.2019.00716

872 Zhang C, Zhang M, Wang S, Han R, Cao Y, Hua W, Mao Y, Zhang X, Pang X, Wei C, Zhao G, 873 Chen Y, Zhao L. 2010. Interactions between gut microbiota, host genetics and diet relevant to 874 development of metabolic syndromes in mice. The ISME Journal 4(2):232-241

875 DOI:10.1038/ismej.2009.112

876 Zhou J, Nelson TM, Lopez CR, Sarma RR, Zhou SJ, Rollins LA. 2020. A comparison of 877 nonlethal sampling methods for amphibian gut microbiome analyses. Molecular Ecological 878 Resources 20:844-855 DOI:10.1111/1755-0998.13139 
Figure 1

Distribution of the sampling sites (Site $1=$ green circle; Site $2=$ orange triangle; Site 3 = blue square) visited in September 2016.

Known distribution area of the invasive population of Duttaphrynus melanostictus in Toamasina in late 2014 (yellow polygon; modified from Moore et al. (2015)). The black square in the inset map shows the relative position of Tamatave in eastern Madagascar. 


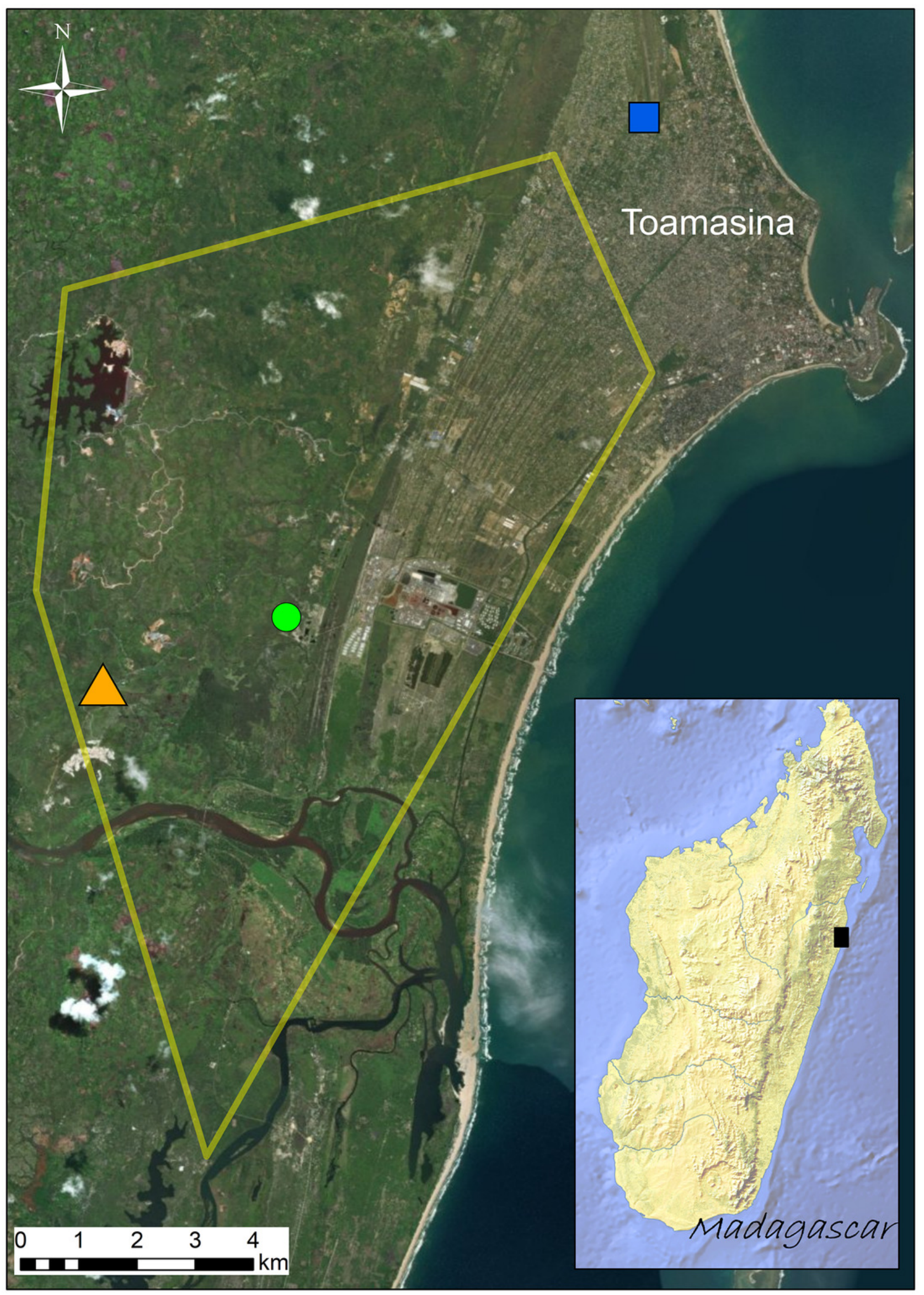




\section{Figure 2}

Skin bacterial diversity and composition of Duttaphrynus melanostictus and Ptychadena mascareniensis across sites

Alpha diversity: (A) OTU Richness. (B) Shannon index. (C) Chaol diversity. (D) Phylogenetic diversity. Different letters indicate significant differences; Beta diversity: (E) Non-metric multidimensional scaling (NMDS) ordination of Weighted Unifrac Distances, (F) Non-metric multidimensional scaling (NMDS) ordination of Unweighted Unifrac Distances; Abundance plots: Composition of the skin bacterial communities including the most abundant taxa from each taxonomic level Phylum (top), Family (middle) and Genus(bottom) in (G) D. melanostictus (left panel) and (H) P. mascareniensis (right panel) across the 3 sites. Photo credit: Angelica Crottini, Javier Lobon-Rovira.
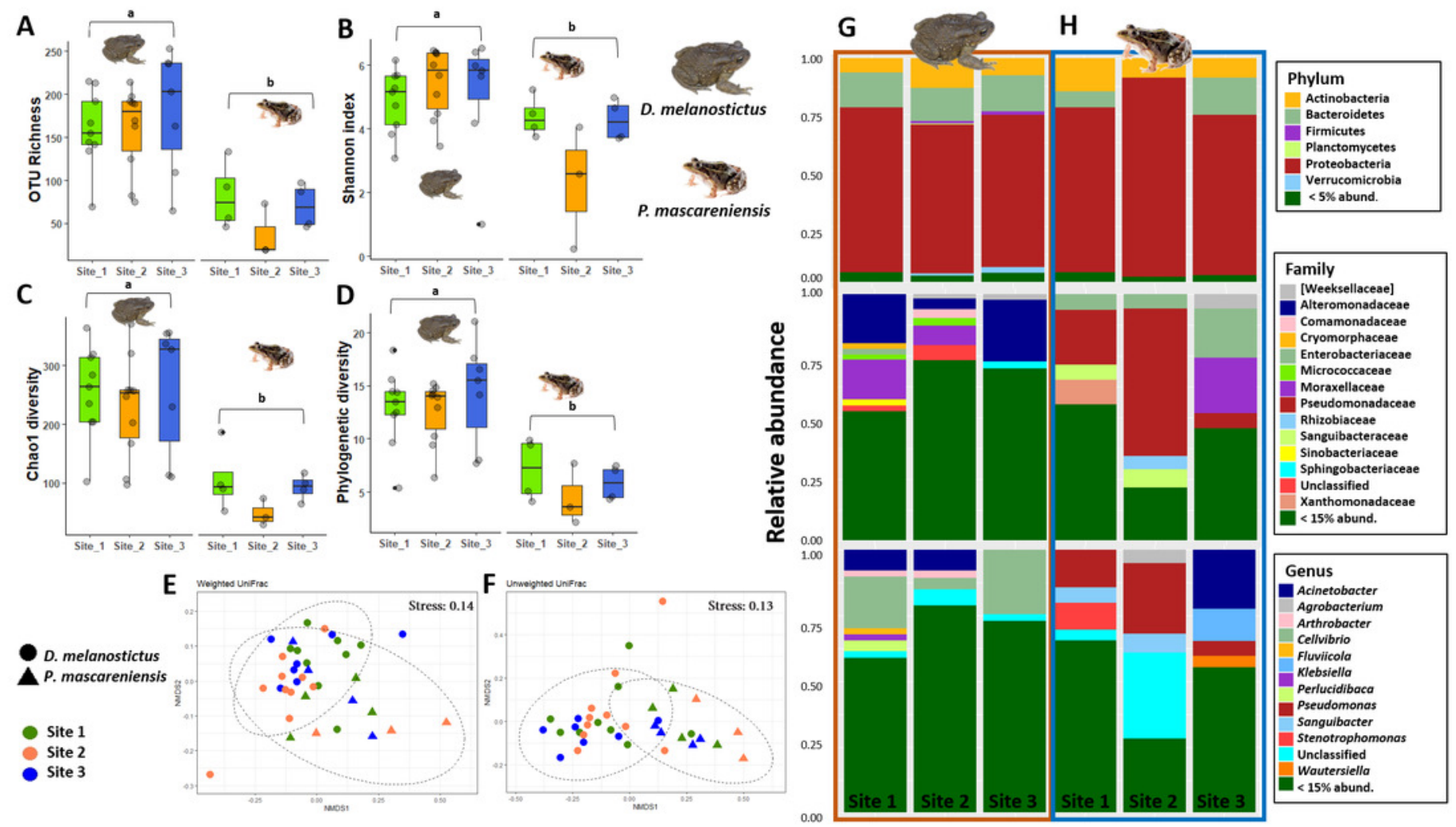
Figure 3

Differentially abundant skin taxa occurring in Duttaphrynus melanostictus (yellow bars) and Ptychadena mascareniensis (blue bars) - LDA scores of detected OTUs in LEfSe analysis.

Photo credit: Angelica Crottini, Javier Lobon-Rovira.

A

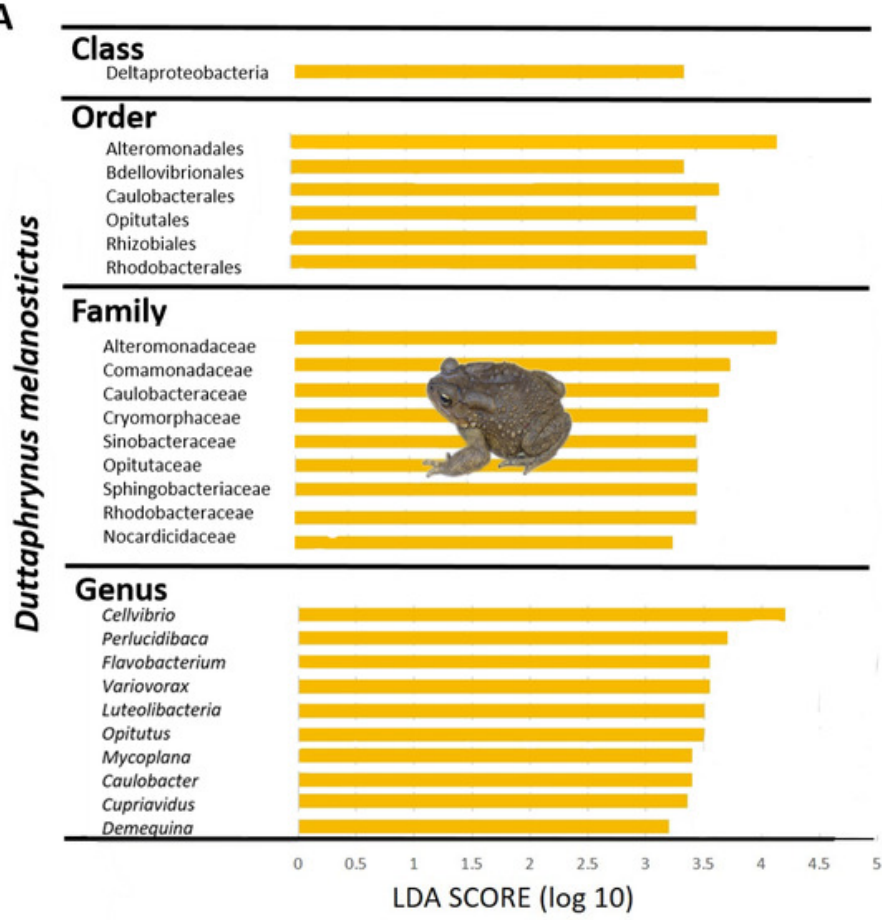

B

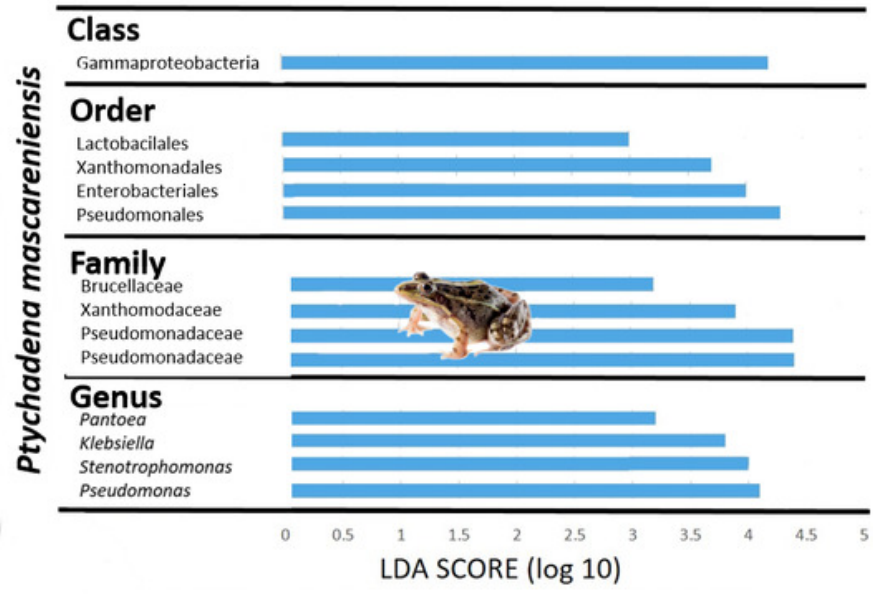




\section{Figure 4}

Skin bacterial diversity and composition of males (green) and females (orange) of Duttaphrynus melanostictus.

Alpha diversity: (A) OTU Richness. (B) Shannon index. (C) Chaol diversity. (D) Phylogenetic diversity. Differente letters indicate signifiant differences; Beta diversity: (E) Non-metric multidimensional scaling (NMDS) ordination of Weighted Unifrac Distances. (F) Non-metric multidimensional scaling (NMDS) ordination of Unweighted Unifrac Distances; Abundance plots: Composition of the skin bacterial communities including the most abundant taxa from each taxonomic level Phylum (top), Family (middle) and Genus (bottom) in (G) females (left orange panel) and (H) males (right green panel). Photo credit: Angelica Crottini.
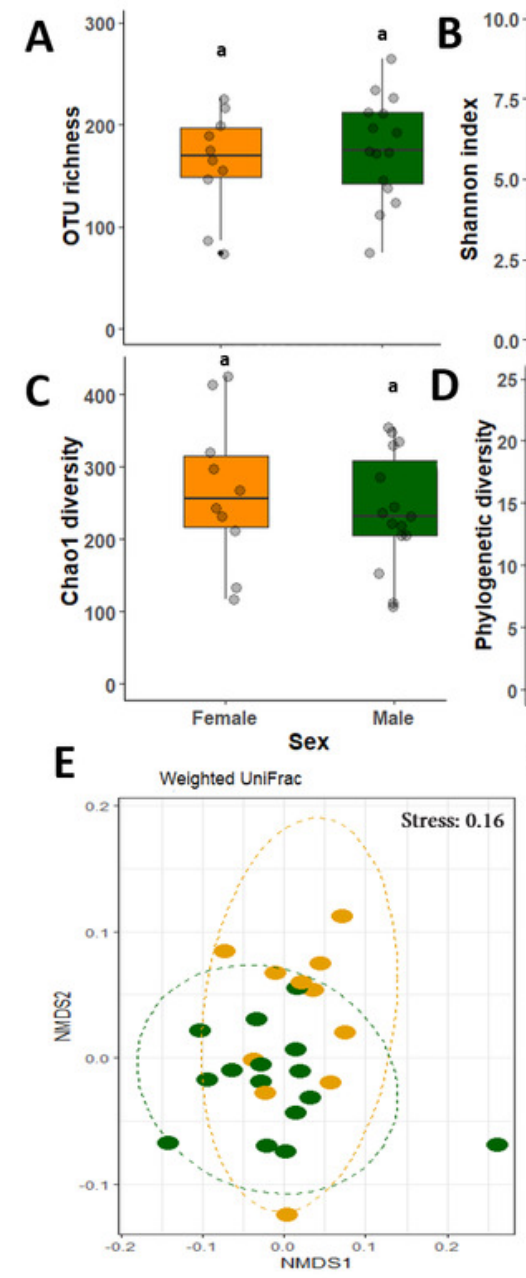
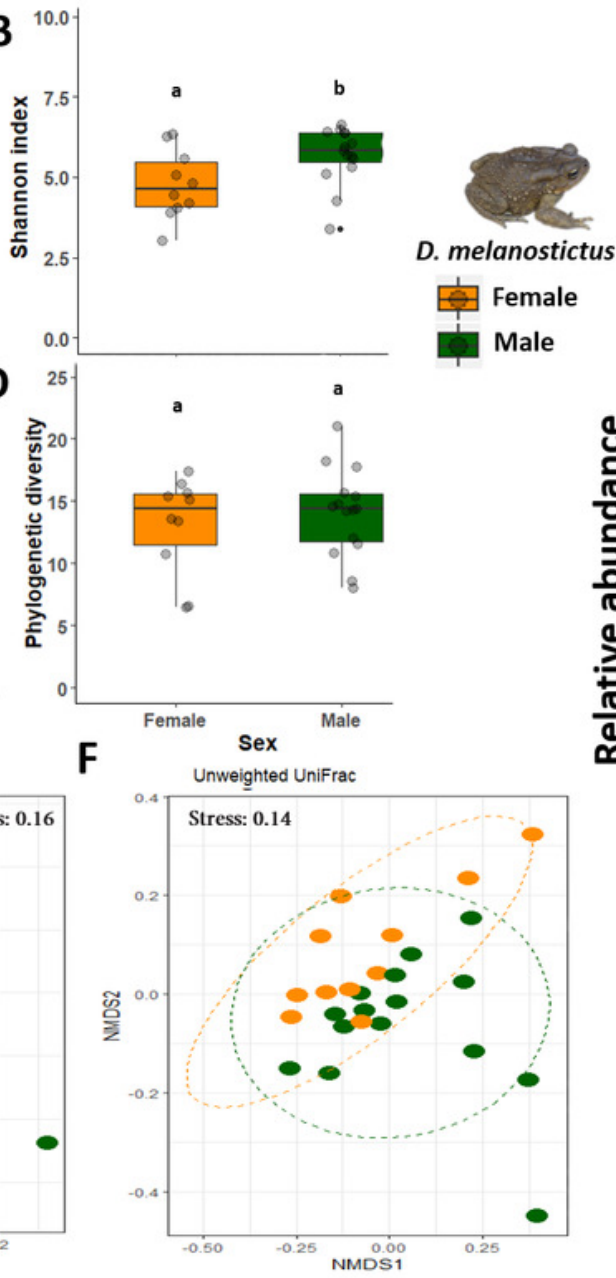

G
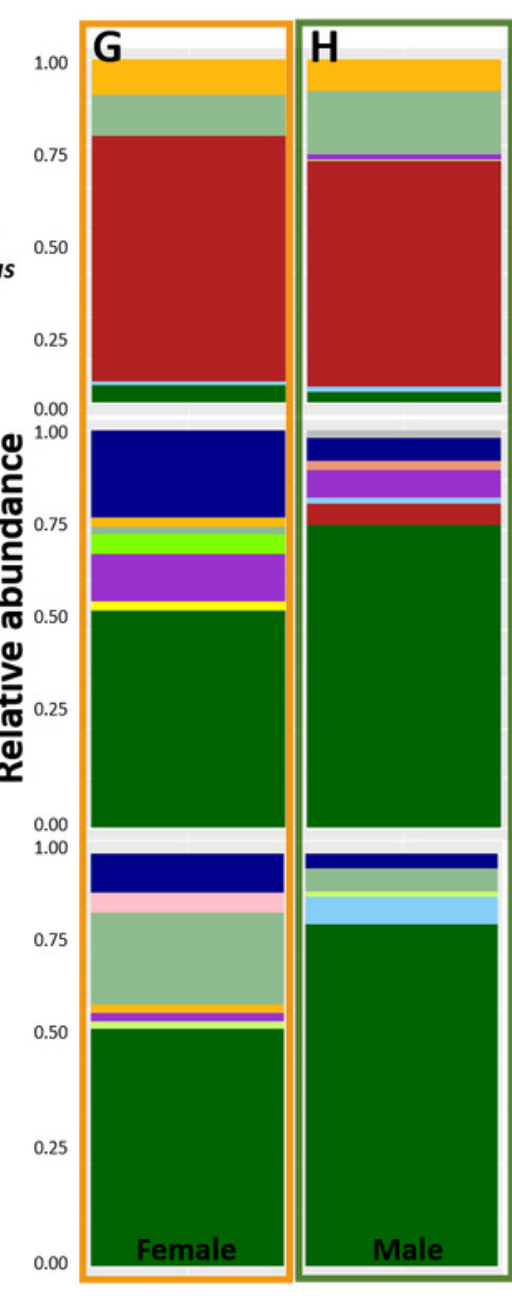

Phylum

Actinobacteria

Bacteroidetes

Firmicutes

Planctomycetes

Proteobacteria

Verrucomicrobia

$<5 \%$ abund.

\begin{tabular}{|l|}
\hline Family \\
[Weeksellaceae] \\
Alteromonadaceae \\
Comamonadaceae \\
Cryomorphaceae \\
Enterobacteriaceae \\
Micrococcaceae \\
Moraxellaceae \\
Sinobacteraceae \\
Sphingobacteriacae \\
Unclassified \\
$<15 \%$ abund. \\
\hline
\end{tabular}

Genus

Acinetobacter

Arthrobacter

Cellvibrio

Fluviicola

Nevskia

Perlucidibaca

Unclassified

$<15 \%$ abund. 


\section{Figure 5}

Gut bacterial diversity and composition of Duttaphrynus melanostictus (yellow) and Ptychadena mascareniensis (blue).

Alpha diversity: (A) OTU Richness. (B) Shannon index. (C) Chaol diversity. (D) Phylogenetic diversity. No significant differences; Beta diversity: (E) Non-metric multidimensional scaling (NMDS) ordination of Weighted Unifrac Distances, (F) Non-metric multidimensional scaling (NMDS) ordination of Unweighted Unifrac Distances; Abundance plots: Composition of the skin bacterial communities including the most abundant taxa from each taxonomic level Phylum (top), Family (middle) and Genus(bottom) in (G) D. melanostictus (left panel) and (H) P. mascareniensis (right panel). Photo credit: Angelica Crottini, Javier Lobon-Rovira. 

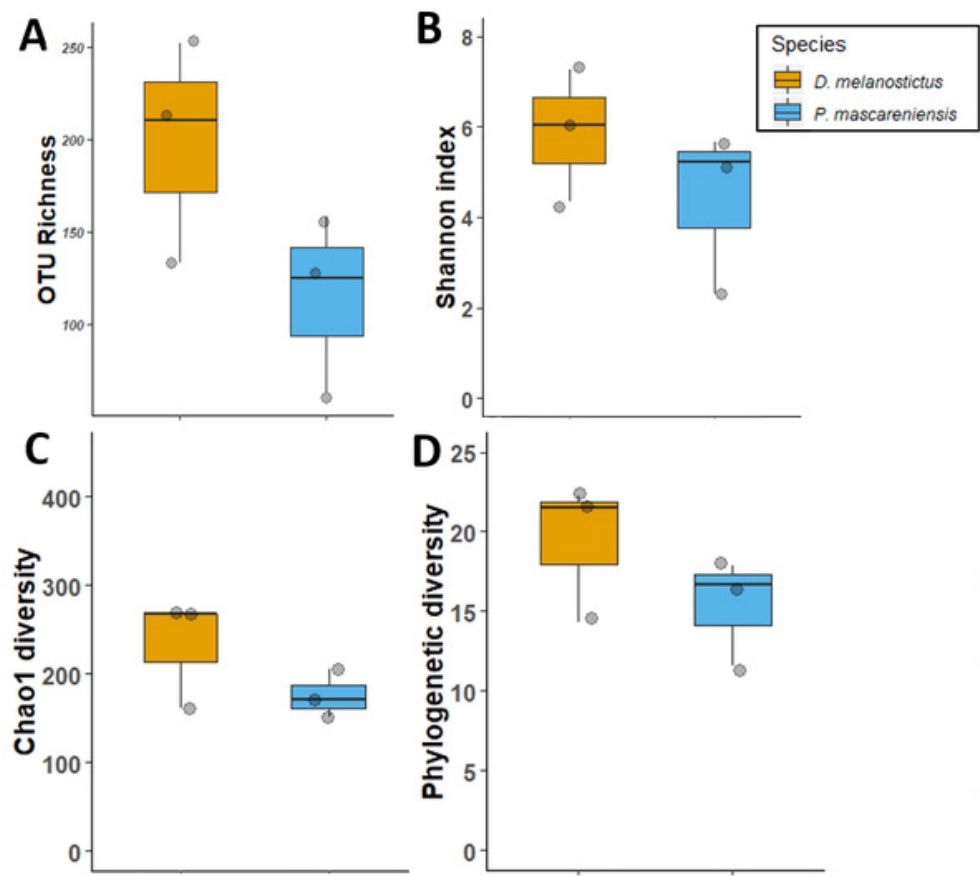

E

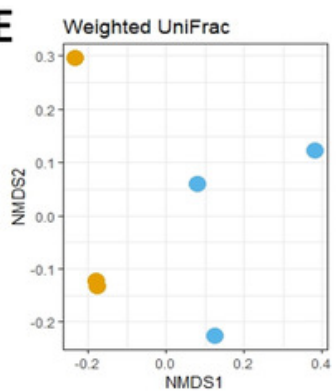

F Unweighted Unifrac

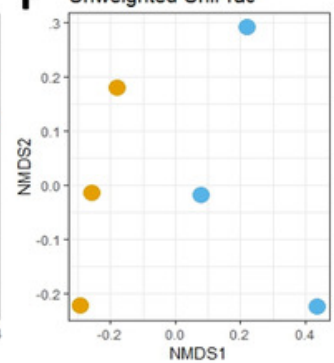

D. melanostictus

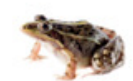

P. mascareniensis

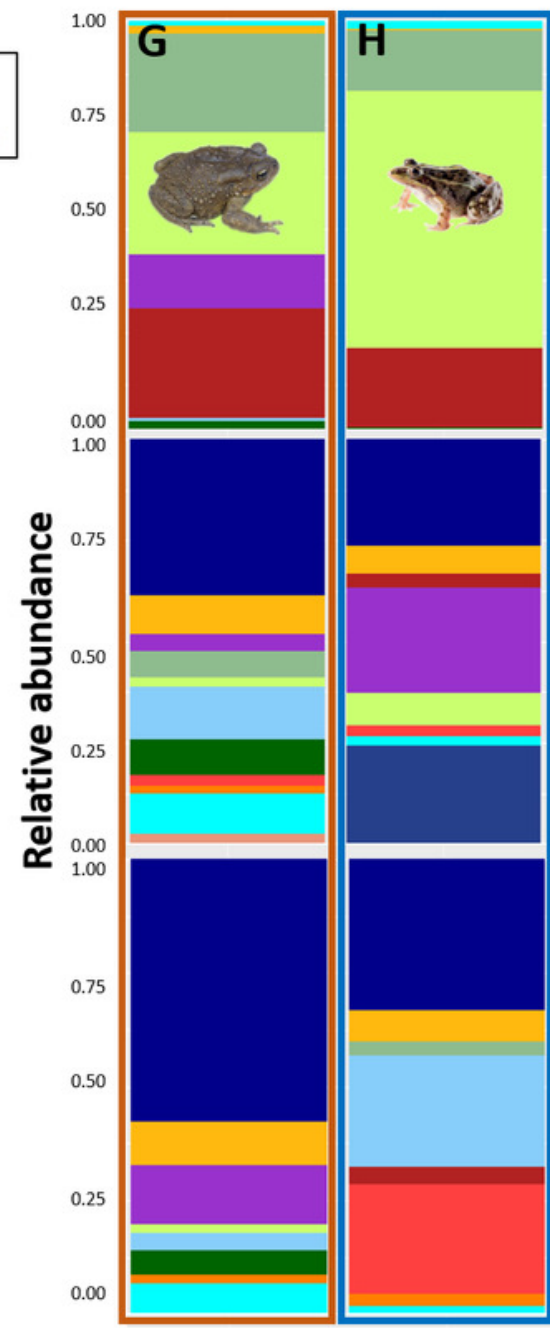

Family

$<5 \%$ abund.

Bacteroidaceae

Burkholderiaceae

Clostridiaceae

Desulfovibrionaceae

Enterobacteriaceae

Fusobacteriaceae

Lachnispiraceae

Porphyromonadaceae

Rikenellaceae

Ruminococcaceae

Streptococcaceae

unclassified

\section{Genus}

$<5 \%$ abund.

Bacteroides

Burkholderia

Cetobacterium

Citrobacter

Clostridium

Desulfovibrio

Klebsiella

Lactococcus

Parabacteroides

unclassified 


\section{Figure 6}

Differentially abundant gut taxa occurring in Duttaphrynus melanostictus with LDA score. No differentially abundant gut taxa were identified in Ptychadena

mascareniensis.

Photo credit: Angelica Crottini.

\section{Phylum}

Fusobacteria

Proteobacteria

\section{Class}

Alphaproteobacteria

Sphingobacteriia

Fusobacteriia

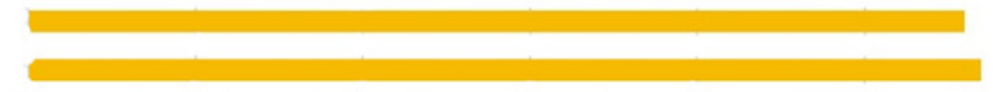

\section{Order}

Turicibacterales

Fusobacteriales

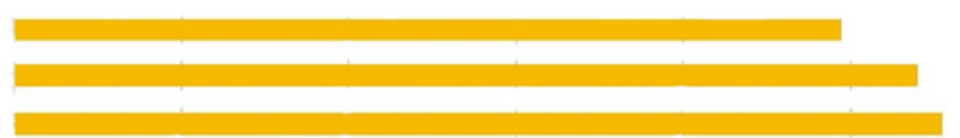

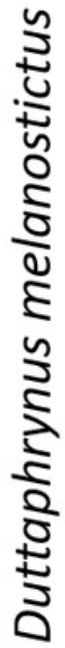

\section{Family}

Christensenellaceae

Turicibacteraceae

Peptostreptococcaceae

Lachnospiraceae

Erysipelotrichaceae

Fusobacteriaceae

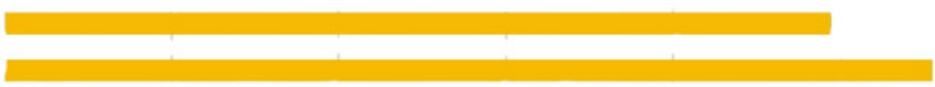

\section{Genus}

Turicibacter

Dorea

Phascolarctobacterium

Ruminococcus

Cetobacterium

Desulfovibrio

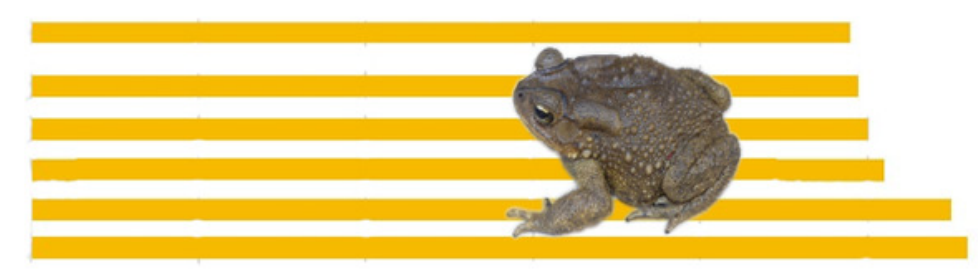

Species

Sphingobacterium multivorum

Bacteroides ovatus

Cetobacterium somerae

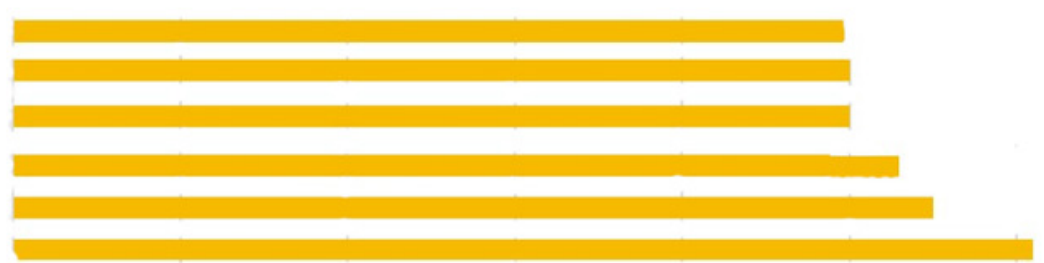

LDA SCORE $(\log 10)$ 